\title{
CONTRIBUTION TO THE KNOWLEDGE OF THE BUTTERFLY FAUNA (LEPIDOPTERA: PAPILIONOIDEA) OF HRVATSKO ZAGORJE, CROATIA
}

\author{
Toni Koren ${ }^{1}$, Boris Lauš ${ }^{1}$, Martina Šašić ${ }^{2}$, Iva Mihoci ${ }^{2}$, Ana Štih ${ }^{1}$, \\ Petra Bralić ${ }^{3}$ \& Stanislav Gomboc ${ }^{4}$
}

\author{
${ }^{1}$ Association Hyla, Lipovac I no. 7, HR-10000 Zagreb, Croatia \\ ${ }^{2}$ Croatian Natural History Museum, Demetrova 1, HR-10000 Zagreb, Croatia \\ ${ }^{3}$ Public Institution for the Management of Protected Areas in the Krapina-Zagorje County, Radoboj 8, \\ HR-49232 Radoboj, Croatia \\ ${ }^{4}$ EGEA, Institution for Nature, Tacenska cesta 135A, SI-1133 Ljubljana, Slovenia
}

Koren, T., Lauš, B., Šašić, M., Mihoci, I., Štih, A., Bralić, P. \& Gomboc, S.: Contribution to the knowledge of the butterfly fauna (Lepidoptera: Papilionoidea) of Hrvatsko zagorje, Croatia. Nat. Croat., Vol. 26, No. 2., 167-196, Zagreb, 2017.

During a nine-year survey of the Hrvatsko zagorje region carried out from 2008 until 2016 we recorded 112 butterfly species. Records were supplemented with seven species known only from literature data, which amounted to 119 species representing $60 \%$ of the Croatian butterfly fauna. The highest butterfly diversity was registered on the mountains Ivanščica and Strahinjščica and along the Sutla River valley. Several rare and endangered species were recorded in the region, mostly grassland specialists such as Phengaris teleius, Ph. alcon rebeli, Polyommatus thersites, Euphydryas aurinia and Zerynthia polyxena whose habitats are declining due to changes in the use of grasslands like abandonment or, less frequently, intensification. The population of Lycaena dispar is still locally numerous, but its habitats are now rapidly overgrown with invasive alien plants. The butterfly diversity of Hrvatsko zagorje is high in comparison with the neighbouring region of Haloze in Slovenia. In order to maintain the high butterfly diversity in the region, grasslands and forest edges in the region are in a need of conservation actions and revitalization.

Key words: Lepidoptera, butterfly diversity, Croatia, Hrvatsko zagorje

Koren, T., Lauš, B., Šašić, M., Mihoci, I., Štih, A., Bralić, P. \& Gomboc, S.: Prilog poznavanju faune danjih leptira (Lepidoptera: Papilionoidea) Hrvatskog zagorja, Hrvatska. Nat. Croat., Vol. 26, No. 2., 167-196, Zagreb, 2017.

Tijekom devetogodišnjeg istraživanja danjih leptira regije Hrvatskog zagorja provedenog od 2008. pa do 2016. godine, zabilježili smo 112 vrsta danjih leptira. Nalaze smo nadopunili sa sedam dodatnih vrsta poznatih iz literature. Tih 119 zabilježenih vrsta predstavlja $60 \%$ faune danjih leptira Hrvatske. Najveća raznolikost leptira zabilježena je na planinama Ivanščici i Strahinjščici te u dolini rijeke Sutle. Zabilježili smo i nekoliko rijetkih i ugroženih vrsta, ponajviše travnjačkih specijalista poput Phengaris teleius, Ph. alcon rebeli, Polyommatus thersites, Euphydryas aurinia i Zerynthia polyxena čija su staništa u opadanju zbog promjena u korištenju travnjaka poput zapuštanja, ili rjeđe, pojačanog korištenja. Populacija vrste Lycaena dispar još je uvijek lokalno mnogobrojna, no i njena staništa ubrzano zarastaju od strane invazivnih biljaka. Raznolikost danjih leptira Hrvatskog zagorja mnogo je veća nego raznolikost Haloza, susjedne regije u Sloveniji. Kako bi se održala visoka raznolikost danjih leptira ove regije, potrebne su brze konzervacijske akcije i revitalizacije travnjaka i šumskih rubova.

Ključne riječi: Lepidoptera, raznolikost leptira, Hrvatska, Hrvatsko zagorje 


\section{INTRODUCTION}

Croatia is located at the junction of four large biogeographic zones, which is reflected in great biodiversity on a regional scale, which is also true for butterflies, compared to other European countries. At the same time, the butterfly fauna of the country is relatively under-surveyed (JAKšić, 1988; ŠAšić \& MinocI, 2011). Recent studies targeted mostly the Croatian islands and karstic areas that generally have greater diversity than continental areas (e.g. HABELER, 2008, KučInić et al., 2010, 2014; Koren et al., 2012, Tvrtković et al., 2011, 2012). Thus there are areas where the only knowledge is based on literature or collection data sometimes older than 100 years. One of such regions is Hrvatsko zagorje.

Hrvatsko zagorje is a cultural, historical and geographical region in the north-western part of Croatia, situated between Mt. Macelj, Varaždinsko Topličko hills, Mt. Kalnik, Mt. Medvednica and bounded by the Sutla River in the western side. Climatically, the region has a moderately warm and humid climate with warm summers and cold winters (ŠEGOTA \& FILIPČIĆ, 2003). Steep slopes and higher hills are mainly covered by forests, whereas in the lowland these have been transformed into a mosaic of anthropogenic habitats like pastures, meadows, orchards, arable fields, vineyards, hedges and villages, a process that started in the Middle Ages (VučEtić, 2007). On the southern slopes and shallow soils, dry calcareous grasslands are still present but due to recent agricultural transformations, with no livestock on the small farms, most of these meadows became abandoned and are now in succession and overgrown by shrubs and invasive alien plants. These are now some of the most endangered habitats in this area. In the lowland, humid grasslands or wetlands are present along the alluvial plains of rivers such as the Krapina, Krapinčica, Horvatska, Bednja, Sutla and their tributaries. Wet meadows in broad valleys are better preserved but even these are slowly being overgrown by invasive plant species and shrubs or intensively exploited, some being turned into fields or urbanized by road infrastructure. The best-preserved natural habitats in the region are wet and continental forests. Part of the Hrvatsko zagorje is covered by the Natura 2000 network, which consists of 14 areas important for species and habitat conservation. Among them six areas (upper part of Ivanščica, three areas along the Bednja, the Sutla valley at Razvor and Medvednica) are selected to protect moth and butterfly species like Lycaena dispar, Euplagia quadripunctaria and Phengaris teleius.

The low number of published records is surprising due to the vicinity of Zagreb, where many lepidopterists were active during the last hundred years. The only published data on butterfly species were published more than a century ago by AbAfi-Aigner (1910). These data refer to the surroundings of Krapina. Additional, more dispersed records were published by STEINER (1916), Gušić (1917), Mladinov (1973, 1975), MarčEc (2008), ŠAšić \& Minoci (2007), Lorković (2009), Koren \& Jugovic (2012) and Koren \& ŠTiH (2013).

The paper presents the results of nine year-long survey of butterflies, which we carried out during different occasions by different authors with the addition of previously published records from the region of Hrvatsko zagorje. This contribution does not consider additional collection material represented in museum and other private collections, except for the authors' collections.

\section{MATERIALS AND METHODS}

Field surveys were carried out during the last 9 years, from 2008 to 2016 with more than 100 field days. Topography and habitat types were used to select the most suitable localities in the region. A total of 292 localities were visited during this survey, while favourable and best-preserved localities were visited several times (Fig. 1, Appendix I). Between 2008 and 2015 field data were obtained more or less at random, while in 2016 targeted surveys were carried out in the least visited areas in order to collect additional data about the butterflies of the region. Field data were entered into an Excel table and basic statistics were calculated. The spatial processing and visualisation of data were done in the program ARC GIS desktop. The EEA 10x10 km reference grid was used in order to present species diversity. Butterflies were identified using a standard field guide (Tolman \& LEWINGTON, 2008). Additionally, specimens of the genera Leptidea, Colias, Melitaea and Plebejus were collected and their genitalia were examined for correct identifications. The nomenclature of the butterflies is given according to DE Jong et al. (2014) and of the genus Leptidea according to Dinca et al. (2011). 


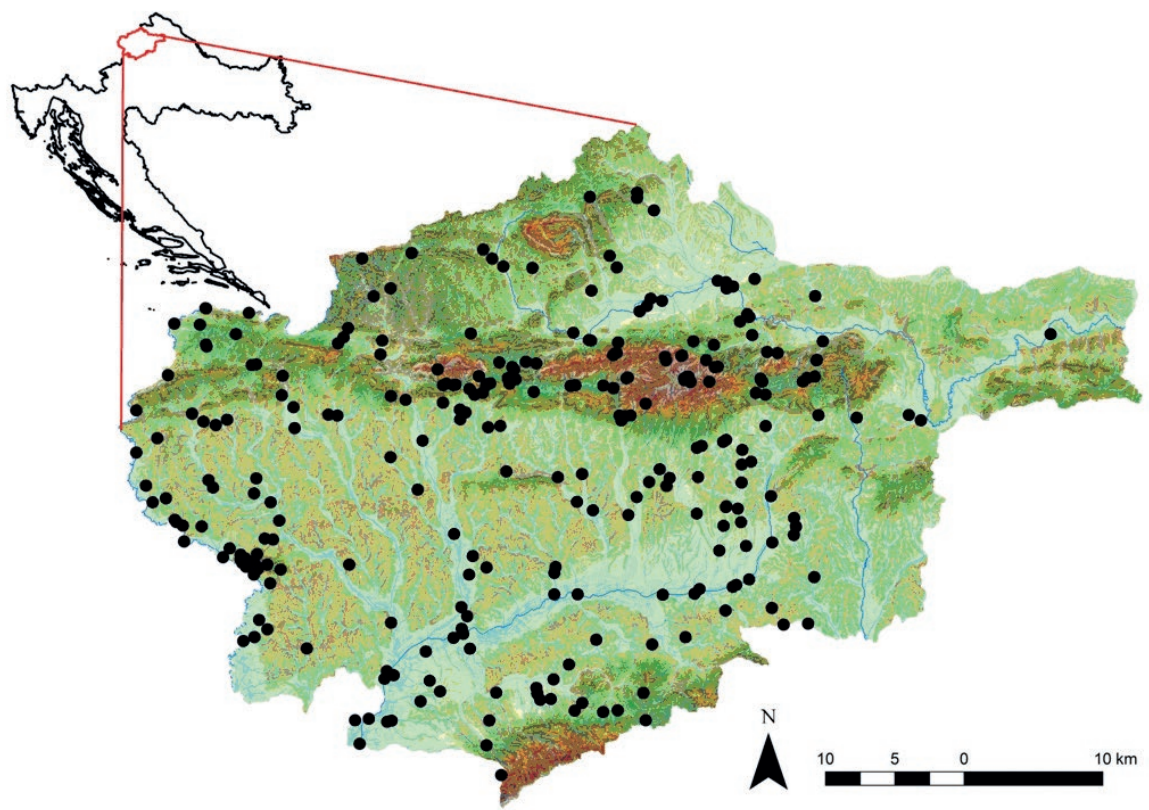

Fig. 1. Surveyed area of Hrvatsko zagorje, Croatia. Black dots represent localities surveyed.

\section{RESULTS}

More than 3300 records across the region were collected during this survey, representing 112 butterfly species. In the overview of the published data for the region, records of 99 butterfly species were found (Abafi-Aigner, 1910; Steiner, 1916; Gušić, 1917; Mladinov, 1973, 1975; MarčEc, 2008; ŠAšić \& Minoci, 2007; Lorković, 2009; Koren \& Jugovic, 2012, Koren \& ŠTiH, 2013) including seven additional species, which were not found during this study. This represents a total of 119 butterfly species found in Hrvatsko zagorje or $60 \%$ of known butterfly fauna of Croatia. Six species were not recorded during the surveys: Aporia crataegi (Linnaeus, 1758), Colias myrmidone (Esper, 1781), Lysandra coridon (Poda, 1761), Argynnis niobe (Linnaeus, 1758), Euphydryas maturna (Linnaeus, 1758) and Hipparchia semele (Linnaeus, 1758). On the other hand, 19 species were recorded for the first time in the region (Tab. 1).

Although the number of registered species is relatively high, it is important to emphasize that many species are represented by only one record or a few records for the region (e.g. Abafi-Aigner 1910, Marčec 2008). Additionally, the recent publications of MarčEc (2008) and Lorković (2009) mostly represent data collected more than 50 years ago.

The region is covered by 33 EEA $10 \times 10 \mathrm{~km}$ reference grid squares, 8 of which are border squares with smaller areas of Hrvatsko zagorje and without any butterfly records (Fig. 2). Overview of the number of species by squares shows that most of the squares are occupied by 21-40 species. In only one square more than 80 species were recorded, in three 61-80 species, in five 41-60 species, in 12 2140 species, and in four $12-20$ species.

The five squares with the highest butterfly diversity include mountainous areas on Strahinjčica (845,9 $\mathrm{m}$ a.s.1.) and Ivanščica (1.060,0 $\mathrm{m}$ a.s.1.) mountains, with diverse hillside and lowland parts along rivers, and the diverse Risvica and Cesar hill (509,0 m a.s.1.) also with lower parts along the Sutla River. The area of these five squares is characterized by diverse habitats; deciduous, coniferous and mixed forests, hedges, thermophilic, mesophilic and wet grasslands and meadows, and agricultural areas with settlements. 
The square with the highest recorded diversity, 83 species, includes Strahinjščica mountain and parts of Macelj mountain. The richest locality within this square was Gorjani Sutinski settlement, with 43 recorded butterfly species. This locality is characterised by thermophilic meadows with hedges and scattered shrubs on the southern slopes of Strahinjčica mountain, in the vicinity of mixed oak and beech forest. The next two squares by species richness have 77 recorded species. One includes the Sutla River and the important landscape "Zelenjak - Risvica and Cesar Hill" with surroundings. This square also includes the locality with the highest recorded butterfly diversity in the whole research area, Mihanovićev Dol settlement, along the Sutla River towards Zelenjak restaurant, with 60 recorded species. There is a mixture of diverse habitats on a small surface area, like the Sutla River with surrounding vegetation with willow trees, wet meadows at river banks and dry meadows on the edges of thermophilic oak, beach and conifer forest on the south-western slopes of Cesar Hill. The other square with 77 species includes eastern parts of Strahinjščica and western parts of Ivanščica mountain. The highest species diversity was recorded again close to Gorjani Sutinski settlement, Smrečki hamlet surroundings 2, with 40 species. Habitats here are wet meadows along a small creek and a fishpond, surrounded by oak and beech forest. Two more squares include the central (66 species) and eastern parts (55 species) of Ivanščica mountain with lowlands along the Bednja River.

Several species have been found at only one locality or a few localities and can be considered as rare or locally distributed in the region (Tab. 1). Species found at only 1-3 localities are: Carcharodus alceae (Esper, 1780), Spialia sertorius (Hoffmannsegg, 1804), Leptidea juvernica Williams, 1946, Pieris balcana (Lorković, 1970), Pontia edusa (Fabricius 1777), Cupido decolorata (Staudinger 1886), Phengaris alcon (Denis \& Schiffermüller, 1775), Phengaris teleius (Bergsträsser, 1779), Polyommatus daphnis (Denis \& Schiffermüller, 1775), Satyrium acaciae (Fabricius, 1787), Satyrium ilicis (Esper, 1779), Satyrium pruni (Linnaeus, 1758), Satyrium spini (Denis \& Schiffermüller, 1775), Thecla betulae (Linnaeus, 1758), Boloria selene (Denis \& Schiffermüller, 1775), Brenthis ino (Rottemburg, 1775), Hipparchia fagi (Scopoli, 1763), Lasiommata maera (Linnaeus, 1758), Melitaea diamina (Lang, 1789), Melitaea ornata Christoph, 1893 and Pyronia tithonus (Linnaeus, 1767).

Tab. 1. List of recorded species with locality numbers and species data from literature. Locality numbers correspond to the ones given in the Appendix 1.

\begin{tabular}{|c|c|c|c|}
\hline No & List of species & Locality number & Literature \\
\hline \multicolumn{4}{|c|}{ Hesperiidae } \\
\hline 1. & $\begin{array}{l}\text { Carcharodus alceae (Esper, } \\
1780 \text { ) }\end{array}$ & 72 & \\
\hline 2. & $\begin{array}{l}\text { Carcharodus floccifera (Zeller, } \\
\text { 1847) }\end{array}$ & $153,227,275,291$ & \\
\hline 3. & $\begin{array}{l}\text { Carterocephalus palaemon } \\
\text { (Pallas, 1771) }\end{array}$ & $108,142,143,151,190$ & \\
\hline 4. & Erynnis tages (Linnaeus, 1758) & $\begin{array}{l}4,5,7,9,16,19,27,28,29,33,34,41,42 \\
45,49,76,78,81,97,101,103,105,119 \\
125,129,134,143,147,156,173,177 \\
195,239,243,244,272,281,287,289,292\end{array}$ & Abafi-Aigner 1910 \\
\hline 5. & $\begin{array}{l}\text { Hesperia comma (Linnaeus, } \\
\text { 1758) }\end{array}$ & $34,120,128,129$ & Abafi-Aigner 1910 \\
\hline 6. & $\begin{array}{l}\text { Heteropterus morpheus (Pallas, } \\
1771 \text { ) }\end{array}$ & $\begin{array}{l}4,9,29,34,120,126,135,148,162,168 \\
173,179,206,243,259,271,274\end{array}$ & \\
\hline
\end{tabular}




\begin{tabular}{|c|c|c|c|}
\hline No & List of species & Locality number & Literature \\
\hline 7. & Ochlodes sylvanus (Esper, 1777) & $\begin{array}{l}7,8,9,10,11,12,15,18,19,23,24,29 \\
30,33,34,36,39,40,44,45,48,49,50 \\
57,60,76,78,82,83,85,93,97,103,104, \\
106,108,120,121,129,142,147,148 \\
160,169,173,179,192,198,209,211 \\
223,224,225,227,231,239,243,244 \\
247,258,262,263,270,275,277,278 \\
287,290,291\end{array}$ & $\begin{array}{l}\text { AbAFi-Aigner 1910, } \\
\text { MarČEC 2008, } \\
\text { MLADINOv 1975 }\end{array}$ \\
\hline 8. & $\begin{array}{l}\text { Pyrgus armoricanus (Oberthür, } \\
\text { 1910) }\end{array}$ & $15,28,50,239$ & MARČEC 2008 \\
\hline 9. & Pyrgus malvae (Linnaeus, 1758) & $\begin{array}{l}3,7,8,26,28,34,45,49,76,78,83,90 \\
103,105,106,115,119,121,129,134 \\
143,148,153,156,157,160,169,173 \\
176,177,198,227,241,243,247,249 \\
250,259,275,277,291\end{array}$ & $\begin{array}{l}\text { Abafi-Aigner 1910, } \\
\text { MLADINOv } 1975\end{array}$ \\
\hline 10. & $\begin{array}{l}\text { Spialia sertorius (Hoff- } \\
\text { mannsegg, 1804) }\end{array}$ & 78,129 & \\
\hline 11. & $\begin{array}{l}\text { Thymelicus lineola (Ochsenhe- } \\
\text { imer, 1808) }\end{array}$ & 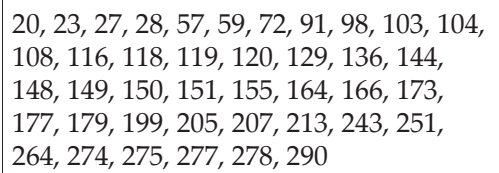 & \\
\hline 12. & $\begin{array}{l}\text { Thymelicus sylvestris (Poda, } \\
\text { 1761) }\end{array}$ & $\begin{array}{l}11,20,23,27,34,39,42,81,94,99,100 \\
112,113,117,136,143,144,146,149 \\
150,155,158,164,165,173,175,178 \\
179,186,189,196,199,205,239,243 \\
244,269,274,276,277,278,281,287\end{array}$ & MARČEC 2008 \\
\hline \multicolumn{4}{|c|}{ Papilionidae } \\
\hline 13. & $\begin{array}{l}\text { Iphiclides podalirius (Linnaeus, } \\
1758 \text { ) }\end{array}$ & $\begin{array}{l}8,13,16,19,30,34,41,45,49,50,51,55 \\
66,77,83,86,90,91,97,98,101,103, \\
105,109,120,129,131,135,136,149 \\
150,164,166,168,170,174,179,180 \\
185,186,188,189,195,197,213,231 \\
232,239,244,256,259,262,271,274 \\
280,283,287,289\end{array}$ & $\begin{array}{l}\text { ABAFI-Aigner 1910, } \\
\text { MARČEc } 2008\end{array}$ \\
\hline 14. & Papilio machaon Linnaeus, 1758 & $\begin{array}{l}8,14,34,49,55,60,77,83,86,90,105, \\
108,109,113,120,125,128,129,135,142, \\
188,219,239,258\end{array}$ & $\begin{array}{l}\text { ABAFi-Aigner 1910, } \\
\text { MARČEc } 2008\end{array}$ \\
\hline 15. & $\begin{array}{l}\text { Parnassius mnemosyne } \\
\text { (Linnaeus, 1758) }\end{array}$ & $\begin{array}{l}\text { 19, 41, 66, 134, 142, 143, 181, 183, 192, } \\
210,211,212,219,221,222,225,234 \\
238,265\end{array}$ & $\begin{array}{l}\text { AbAFi-Aigner 1910, } \\
\text { MARČEC 2008, } \\
\text { MLADINOV } 1973\end{array}$ \\
\hline 16. & $\begin{array}{l}\text { Zerynthia polyxena (Denis \& } \\
\text { Schiffermüller, 1775) }\end{array}$ & $12,19,63,76,97,103$ & $\begin{array}{l}\text { ABAFI-Aigner 1910, } \\
\text { MARČEC, } 2008\end{array}$ \\
\hline
\end{tabular}




\begin{tabular}{|c|c|c|c|}
\hline No & List of species & Locality number & Literature \\
\hline \multicolumn{4}{|c|}{ Pieridae } \\
\hline 17. & $\begin{array}{l}\text { Anthocharis cardamines } \\
\text { (Linnaeus, 1758) }\end{array}$ & $\begin{array}{l}29,30,34,52,55,56,66,83,86,101,103, \\
105,108,109,125,129,143,148,172, \\
177,193,201,203,230,232,239,240, \\
261,267,285,289,292\end{array}$ & $\begin{array}{l}\text { AbAfi-Aigner 1910, } \\
\text { MARČEC } 2008\end{array}$ \\
\hline 18. & $\begin{array}{l}\text { Aporia crataegi (Linnaeus, } \\
1758 \text { ) }\end{array}$ & & $\begin{array}{l}\text { AbAFi-Aigner } 1910, \\
\text { MarČec 2008, } \\
\text { MLAdinov } 1973\end{array}$ \\
\hline 19. & Colias alfacariensis Ribbe, 1905 & $\begin{array}{l}3,8,16,19,27,42,89,121,126,129,134 \\
143,147,173,196,280,281,283\end{array}$ & \\
\hline 20. & Colias croceus (Fourcroy, 1785) & $\begin{array}{l}5,8,15,30,34,40,44,45,51,60,78,84, \\
88,93,96,106,113,124,126,129,140, \\
160,163,169,170,175,186,189,190, \\
208,225,231,233,235,237,243,244, \\
247,259,262,272,278\end{array}$ & $\begin{array}{l}\text { AbAFi-Aigner 1910, } \\
\text { MARČEC } 2008\end{array}$ \\
\hline 21. & Colias hyale (Linnaeus, 1758) & $60,120,129,132,136,170,283$ & MARČEC 2008 \\
\hline 22. & Colias myrmidone (Esper, 1781) & & $\begin{array}{l}\text { ABAfi-Aigner 1910, } \\
\text { MARČEC } 2008\end{array}$ \\
\hline 23. & $\begin{array}{l}\text { Gonepteryx rhamni (Linnaeus, } \\
1758 \text { ) }\end{array}$ & $\begin{array}{l}\text { 4, 7, 8, 11, 19, 20, 23, 29, 30, 31, 33, 34, } \\
\text { 40, 41, 45, 49, 50, 54, 55, 57, 65, 66, 77, } \\
\text { 78, 81, 85, 89, 90, 91, 97, 98, 99, 100, 101, } \\
\text { 103, 104, 105, 106, 107, 108, 115, 125, } \\
\text { 126, 129, 138, 139, 142, 143, 144, 145, } \\
\text { 146, 148, 149, 150, 151, 155, 170, 172, } \\
\text { 173, 177, 178, 180, 182, 185, 188, 189, } \\
\text { 190, 191, 192, 194, 196, 197, 201, 217, } \\
219,225,227,240,243,244,247,261, \\
262,267,274,278,280,282,283,287, \\
289,292\end{array}$ & $\begin{array}{l}\text { ABAFI-Aigner 1910, } \\
\text { MARČEC } 2008\end{array}$ \\
\hline 24. & $\begin{array}{l}\text { Leptidea juvernica Williams, } \\
1946\end{array}$ & 173,198 & MARČEC 2008 \\
\hline 25. & Leptidea morsei (Fenton, 1882) & & LoRKOVIĆ 1993 \\
\hline 26. & $\begin{array}{l}\text { Leptidea sinapis (Linnaeus, } \\
1758 \text { ) }\end{array}$ & $\begin{array}{l}2,6,7,8,10,11,14,15,19,21,23,27,28, \\
29,30,33,34,35,36,39,41,45,49,50, \\
51,54,58,84,85,88,90,97,98,99,103, \\
104,105,106,108,116,119,120,123, \\
125,128,129,134,136,142,143,144, \\
145,148,150,151,157,160,167,173, \\
177,178,186,190,194,196,198,201, \\
205,209,230,231,232,233,237,238, \\
240,243,244,247,249,252,261,262, \\
264,278,279,287\end{array}$ & $\begin{array}{l}\text { AbAFI-Aigner 1910, } \\
\text { MARČEC } 2008\end{array}$ \\
\hline 27. & Pieris balcana (Lorković, 1970) & 288 & LoRKOVIĆ 1989 \\
\hline 28. & $\begin{array}{l}\text { Pieris brassicae (Linnaeus, } \\
1758 \text { ) }\end{array}$ & $\begin{array}{l}3,15,24,29,33,34,40,41,43,45,49,50, \\
51,68,73,90,98,101,103,104,105,108, \\
110,113,120,126,128,135,139,141, \\
148,172,180,185,192,194,197,198, \\
210,211,217,219,222,225,234,258, \\
269,273,278,279,287\end{array}$ & $\begin{array}{l}\text { ABAFI-Aigner 1910, } \\
\text { MARČEC } 2008\end{array}$ \\
\hline
\end{tabular}




\begin{tabular}{|c|c|c|c|}
\hline No & List of species & Locality number & Literature \\
\hline 29. & Pieris mannii (Mayer, 1851) & $\begin{array}{l}28,29,34,45,77,95,99,120,151,197, \\
202,215,222,223,225,235,243,244, \\
262,278\end{array}$ & MARČEC 2008 \\
\hline 30. & Pieris napi (Linnaeus, 1758) & $\begin{array}{l}2,6,8,18,25,29,31,33,34,40,41,43, \\
45,49,50,51,61,68,73,75,76,78,79, \\
81,83,89,90,92,95,98,99,103,106, \\
107,108,113,115,119,128,129,133, \\
135,139,142,144,147,148,149,154, \\
155,156,160,161,164,169,170,172, \\
173,182,188,190,191,192,194,196, \\
197,206,209,210,211,213,215,216, \\
217,219,222,225,231,233,234,238, \\
242,243,244,248,249,254,258,260, \\
262,264,266,268,269,278,279,282, \\
284,287,289,292\end{array}$ & $\begin{array}{l}\text { ABAFI-Aigner 1910, } \\
\text { MARČEC } 2008\end{array}$ \\
\hline 31. & Pieris rapae (Linnaeus, 1758) & $\begin{array}{l}1,3,6,8,15,19,25,27,28,29,30,32,33, \\
34,35,40,41,42,44,45,49,50,51,60 \\
64,72,78,88,95,98,99,103,104,106, \\
107,116,120,123,127,129,134,136, \\
139,140,144,146,149,155,156,157, \\
159,163,164,165,170,173,180,184, \\
186,188,189,192,195,199,213,217, \\
225,229,231,235,239,240,242,249, \\
259,268,269,271,273,274,278,281, \\
283,287,289,292\end{array}$ & $\begin{array}{l}\text { ABAFI-AignER 1910, } \\
\text { MARČEC } 2008\end{array}$ \\
\hline 32. & Pontia edusa (Fabricius, 1777) & 113 & MARČEC 2008 \\
\hline \multicolumn{4}{|c|}{ Riodinidae } \\
\hline 33. & $\begin{array}{l}\text { Hamearis lucina (Linnaeus, } \\
1758 \text { ) }\end{array}$ & $\begin{array}{l}29,33,34,45,78,81,86,103,108,109, \\
149,220,271,274\end{array}$ & \\
\hline \multicolumn{4}{|c|}{ Lycaenidae } \\
\hline 34. & $\begin{array}{l}\text { Aricia agestis (Denis \& } \\
\text { Schiffermüller, 1775) }\end{array}$ & $\begin{array}{l}29,34,45,49,97,103,128,129,143,243 \\
278\end{array}$ & MARČEC 2008 \\
\hline 35. & $\begin{array}{l}\text { Callophrys rubi (Linnaeus, } \\
1758 \text { ) }\end{array}$ & $\begin{array}{l}\text { 7, 19, 29, 30, 49, 77, 103, 105, 129, 146, } \\
172,180,243,279,289,292\end{array}$ & Abafi-Aigner 1910 \\
\hline 36. & $\begin{array}{l}\text { Celastrina argiolus (Linnaeus, } \\
1758 \text { ) }\end{array}$ & $\begin{array}{l}25,27,29,33,34,41,45,49,58,77,90, \\
98,103,105,108,109,110,111,113,116, \\
123,125,129,135,139,141,142,143, \\
148,149,155,165,166,167,184,188, \\
192,194,197,201,215,217,219,223, \\
225,226,227,232,258,261,267,274, \\
282,288,289\end{array}$ & $\begin{array}{l}\text { ABAFI-Aigner 1910, } \\
\text { MARČEC } 2008\end{array}$ \\
\hline 37. & Cupido minimus (Fuessly, 1775) & $\begin{array}{l}26,28,75,87,103,114,124,129,143, \\
178,186,205,270\end{array}$ & \\
\hline 38. & $\begin{array}{l}\text { Cupido alcetas (Hoffmannsegg, } \\
1804 \text { ) }\end{array}$ & $90,93,143,153,159$ & $\begin{array}{l}\text { LORKOVIĆ } 2009, \\
\text { MARČEC } 2008\end{array}$ \\
\hline
\end{tabular}




\begin{tabular}{|c|c|c|c|}
\hline No & List of species & Locality number & Literature \\
\hline 39. & Cupido argiades (Pallas, 1771) & $\begin{array}{l}1,6,7,15,16,19,28,29,30,34,40,45 \\
50,69,78,81,83,95,99,103,105,107 \\
111,112,113,116,120,124,126,129 \\
142,143,144,148,155,157,167,173 \\
178,196,198,202,205,233,235,236 \\
237,241,243,244,249,260,262,278 \\
283,287\end{array}$ & $\begin{array}{l}\text { ABAFI-Aigner 1910, } \\
\text { MARČEC } 2008\end{array}$ \\
\hline 40. & $\begin{array}{l}\text { Cupido decolorata (Staudinger, } \\
\text { 1886) }\end{array}$ & $88,281,287$ & LoRKоvić 2009 \\
\hline 41. & $\begin{array}{l}\text { Cyaniris semiargus (Rottem- } \\
\text { burg, 1775) }\end{array}$ & $\begin{array}{l}7,8,16,19,134,143,153,171,173,179 \\
206,213,224,243,272,277,281,283,287\end{array}$ & \\
\hline 42. & $\begin{array}{l}\text { Favonius quercus (Linnaeus, } \\
1758 \text { ) }\end{array}$ & $34,49,96,102$ & $\begin{array}{l}\text { ABAFI-Aigner 1910, } \\
\text { MARČEC } 2008\end{array}$ \\
\hline 43. & $\begin{array}{l}\text { Glaucopsyche alexis (Poda, } \\
\text { 1761) }\end{array}$ & $103,108,143,190$ & LoRKOvić 2009 \\
\hline 44. & $\begin{array}{l}\text { Lycaena alciphron (Rottemburg, } \\
1775 \text { ) }\end{array}$ & $70,93,120,137,153$ & \\
\hline 45. & Lycaena dispar (Haworth, 1802) & $\begin{array}{l}3,10,11,16,19,22,26,34,44,48,50,53 \\
59,67,69,70,78,84,90,107,121,126, \\
132,137,142,143,151,155,156,160, \\
169,170,198,204,206,231,233,236, \\
237,243,244,250,260,262,271,275,277\end{array}$ & $\begin{array}{l}\text { Abafi-Aigner 1910, } \\
\text { Marčec } 2008\end{array}$ \\
\hline 46. & $\begin{array}{l}\text { Lycaena hippothoe (Linnaeus, } \\
\text { 1761) }\end{array}$ & $\begin{array}{l}23,26,36,47,78,157,169,171,206,241 \\
243,247,262,275\end{array}$ & \\
\hline 47. & $\begin{array}{l}\text { Lycaena phlaeas (Linnaeus, } \\
\text { 1761) }\end{array}$ & $\begin{array}{l}15,28,34,45,60,76,97,103,109,134, \\
136,143,160,170,179,199,247,262,291\end{array}$ & $\begin{array}{l}\text { AbAfi-Aigner 1910, } \\
\text { MARČEC 2008, } \\
\text { STEINER } 1916\end{array}$ \\
\hline 48. & Lycaena tityrus (Poda, 1761) & $\begin{array}{l}10,11,12,29,34,36,40,45,49,76,78 \\
83,97,103,107,143,146,151,156,163 \\
167,168,169,177,196,206,219,220, \\
224,233,235,241,243,262,263,270,278\end{array}$ & $\begin{array}{l}\text { AbAFi-AignER 1910, } \\
\text { MARČEC } 2008\end{array}$ \\
\hline 49. & $\begin{array}{l}\text { Lycaena virgaureae (Linnaeus, } \\
1758 \text { ) }\end{array}$ & $29,98,116,146,148,151,279$ & \\
\hline 50. & $\begin{array}{l}\text { Phengaris alcon (Denis \& } \\
\text { Schiffermüller, 1775) }\end{array}$ & 116,247 & MARČEC 2008 \\
\hline 51. & $\begin{array}{l}\text { Phengaris arion (Linnaeus, } \\
1758 \text { ) }\end{array}$ & $9,29,30,34,49,98,262$ & $\begin{array}{l}\text { ABAFI-Aigner 1910, } \\
\text { MARČEC } 2008\end{array}$ \\
\hline 52. & $\begin{array}{l}\text { Phengaris teleius (Bergsträsser, } \\
\text { 1779) }\end{array}$ & 247,260 & \\
\hline 53. & Plebejus argus (Linnaeus, 1758) & $\begin{array}{l}3,4,5,9,12,15,16,19,20,25,27,35,38 \\
39,40,42,44,50,59,62,67,84,90,93 \\
112,120,124,126,129,132,148,160 \\
168,170,176,179,243,258,270,278 \\
282,287\end{array}$ & $\begin{array}{l}\text { Abafi-Aigner 1910, } \\
\text { MARČEC } 2008\end{array}$ \\
\hline
\end{tabular}




\begin{tabular}{|c|c|c|c|}
\hline No & List of species & Locality number & Literature \\
\hline 54. & $\begin{array}{l}\text { Plebejus argyrognomon } \\
\text { (Bergsträsser, 1779) }\end{array}$ & $5,15,280,287$ & $\begin{array}{l}\text { ABAFI-Aigner 1910, } \\
\text { LORKOVIĆ 2009, } \\
\text { MARČEC } 2008\end{array}$ \\
\hline 55. & Plebejus idas (Linnaeus, 1761) & $28,142,188$ & MARČEC 2008 \\
\hline 56. & $\begin{array}{l}\text { Polyommatus bellargus } \\
\text { (Rottemburg, 1775) }\end{array}$ & $76,77,78,85,120,129,151,233$ & АвAFI-Aigner 1910 \\
\hline 57. & Lysandra coridon (Poda, 1761) & & $\begin{array}{l}\text { AbAFi-Aigner 1910, } \\
\text { LoRKOVIĆ } 2009, \\
\text { MARČEC } 2008\end{array}$ \\
\hline 58. & $\begin{array}{l}\text { Lysandra icarus (Rottemburg, } \\
1775 \text { ) }\end{array}$ & $\begin{array}{l}1,4,5,6,7,8,9,10,11,12,15,16,19,20, \\
23,24,25,26,27,28,29,30,32,33,34,35, \\
36,40,42,44,45,47,49,50,51,57,59,60, \\
67,69,70,73,77,78,79,81,85,87,88,89, \\
90,93,95,97,99,100,103,106,107,112, \\
113,117,120,124,126,128,129,130,132, \\
134,136,137,140,143,144,146,151,153, \\
156,157,160,161,164,169,170,171,173, \\
175,176,179,182,188,189,195,196,197, \\
198,199,200,215,219,220,231,235,238, \\
239,243,244,245,250,254,257,258,259, \\
263,270,271,272,273,274,275,276,278, \\
280,281,283,284,286,287,290,291\end{array}$ & $\begin{array}{l}\text { ABAFI-AignER 1910, } \\
\text { MARČEC } 2008\end{array}$ \\
\hline 59. & $\begin{array}{l}\text { Polyommatus thersites } \\
\text { (Cantener, 1835) }\end{array}$ & $\begin{array}{l}7,19,28,49,89,90,103,113,120,124 \\
134,143,144,278\end{array}$ & \\
\hline 60. & $\begin{array}{l}\text { Polyommatus daphnis (Denis \& } \\
\text { Schiffermüller, 1775) }\end{array}$ & 103 & $\begin{array}{l}\text { ABAFI-Aigner 1910, } \\
\text { MARČEC } 2008\end{array}$ \\
\hline 61. & $\begin{array}{l}\text { Satyrium acaciae (Fabricius, } \\
\text { 1787) }\end{array}$ & 29,34 & AbAFi-Aigner 1910 \\
\hline 62. & Satyrium ilicis (Esper, 1779) & 57 & $\begin{array}{l}\text { ABAFI-Aigner 1910, } \\
\text { MARČEC } 2008\end{array}$ \\
\hline 63. & $\begin{array}{l}\text { Satyrium pruni (Linnaeus, } \\
1758 \text { ) }\end{array}$ & $57,189,243$ & Abafi-Aigner 1910 \\
\hline 64. & $\begin{array}{l}\text { Satyrium spini (Denis \& } \\
\text { Schiffermüller, 1775) }\end{array}$ & $129,134,243$ & $\begin{array}{l}\text { AbAFi-Aigner 1910, } \\
\text { MARČEc } 2008\end{array}$ \\
\hline 65. & $\begin{array}{l}\text { Satyrium w-album (Knoch, } \\
\text { 1782) }\end{array}$ & $23,29,34,45,49$ & MARČEC 2008 \\
\hline 66. & Scolitantides orion (Pallas, 1771) & $29,33,108,194$ & $\begin{array}{l}\text { ABAFI-Aigner 1910, } \\
\text { LORKOVIĆ } 2009, \\
\text { MARČEC } 2008\end{array}$ \\
\hline 67. & Thecla betulae (Linnaeus, 1758) & 34 & $\begin{array}{l}\text { ABAFi-Aigner 1910, } \\
\text { MARČEC } 2008\end{array}$ \\
\hline
\end{tabular}




\begin{tabular}{|c|c|c|c|}
\hline No & List of species & Locality number & Literature \\
\hline \multicolumn{4}{|c|}{ Nymphalidae } \\
\hline 68. & Aglais io (Linnaeus, 1758) & $\begin{array}{l}3,4,5,6,8,9,16,19,29,30,31,33,34 \\
35,40,50,52,88,90,91,98,99,103,104, \\
105,107,108,109,110,112,113,120 \\
125,127,128,129,133,139,141,148 \\
152,154,155,163,164,167,170,172, \\
179,180,182,185,188,192,194,196, \\
198,201,204,209,211,213,217,219, \\
224,225,231,242,243,256,259,267, \\
282,284,289,292\end{array}$ & $\begin{array}{l}\text { ABAFI-AIGNER 1910, } \\
\text { MARČEC } 2008\end{array}$ \\
\hline 69. & Aglais urticae (Linnaeus, 1758) & $\begin{array}{l}\text { 12, 29, 34, 44, 47, 49, 57, 73, 77, 97, 108, } \\
120,134,143,146,153,171,172,175, \\
180,181,187,192,201,219,224,225, \\
228,252,253,258,289\end{array}$ & $\begin{array}{l}\text { ABAFI-Aigner 1910, } \\
\text { MARČEC } 2008\end{array}$ \\
\hline 70. & $\begin{array}{l}\text { Apatura ilia (Denis \& } \\
\text { Schiffermüller, 1775) }\end{array}$ & $\begin{array}{l}\text { 12, 34, 50, 68, 74, 100, 137, 142, 144, 146, } \\
148,152,154,159,163,167,198,202 \\
204,207,227,240,243,244,259,273,279\end{array}$ & MARČEC 2008 \\
\hline 71. & Apatura iris (Linnaeus, 1758) & $144,179,188,217,219,279$ & MARČEC 2008 \\
\hline 72. & $\begin{array}{l}\text { Aphantopus hyperantus } \\
\text { (Linnaeus, 1758) }\end{array}$ & $\begin{array}{l}29,33,34,45,49,50,91,98,108,127 \\
134,140,143,149,150,164,178,179 \\
196,197,243,271,274,276,287\end{array}$ & \\
\hline 73. & $\begin{array}{l}\text { Araschnia levana (Linnaeus, } \\
\text { 1758) }\end{array}$ & $\begin{array}{l}6,7,10,19,23,28,29,30,31,32,33,34, \\
37,38,39,40,41,45,50,53,66,67,78 \\
79,84,88,90,98,107,108,110,113,116 \\
123,125,133,135,141,142,143,148 \\
150,151,154,155,159,167,177,179 \\
184,188,192,196,197,201,209,213 \\
215,217,227,229,234,240,242,243 \\
248,249,252,256,259,261,267,268 \\
271,278,282,287\end{array}$ & $\begin{array}{l}\text { ABAFI-Aigner 1910, } \\
\text { MARČEC } 2006\end{array}$ \\
\hline 74. & $\begin{array}{l}\text { Argynnis adippe (Denis \& } \\
\text { Schiffermüller, 1775) }\end{array}$ & $\begin{array}{l}34,45,120,146,149,179,197,211,214 \\
215,223,224,225,278\end{array}$ & MARČEC 2006 \\
\hline 75. & $\begin{array}{l}\text { Argynnis aglaja (Linnaeus, } \\
1758 \text { ) }\end{array}$ & $134,149,179,222,225,274$ & MARČEC 2008 \\
\hline 76. & $\begin{array}{l}\text { Argynnis niobe (Linnaeus, } \\
1758 \text { ) }\end{array}$ & & MarČEC 2008 \\
\hline 77. & $\begin{array}{l}\text { Argynnis pandora (Denis \& } \\
\text { Schiffermüller, 1775) }\end{array}$ & $79,97,197,219$ & \\
\hline 78. & $\begin{array}{l}\text { Argynnis paphia (Linnaeus, } \\
1758 \text { ) }\end{array}$ & $\begin{array}{l}6,34,41,45,49,50,79,107,108,110 \\
116,120,129,139,142,148,155,163 \\
167,188,191,192,194,197,209,217 \\
223,224,225,252,262,274,278,282\end{array}$ & MARČEC 2008 \\
\hline 79. & Boloria dia (Linnaeus, 1767) & $\begin{array}{l}1,6,15,27,29,30,34,37,45,81,95,120 \\
124,126,128,129,134,177,178,179 \\
186,189,199,231,233,235,247,287\end{array}$ & Abafi-Aigner 1910 \\
\hline
\end{tabular}




\begin{tabular}{|c|c|c|c|}
\hline No & List of species & Locality number & Literature \\
\hline 80. & $\begin{array}{l}\text { Boloria euphrosyne (Linnaeus, } \\
1758 \text { ) }\end{array}$ & $146,211,223,238,244$ & MARČEC 2008 \\
\hline 81. & $\begin{array}{l}\text { Boloria selene (Denis \& } \\
\text { Schiffermüller, 1775) }\end{array}$ & 275 & MarČEC 2008 \\
\hline 82. & $\begin{array}{l}\text { Brenthis daphne (Bergsträsser, } \\
1780 \text { ) }\end{array}$ & $\begin{array}{l}11,23,25,33,34,38,39,58,88,91,98 \\
100,103,104,108,109,110,116,120 \\
129,137,139,142,144,146,148,151 \\
160,169,179,188,189,192,219,222, \\
225,229,238,243,256,258,269,270 \\
277,278,279,284,286,287\end{array}$ & MarČEC 2008 \\
\hline 83. & $\begin{array}{l}\text { Brenthis ino (Rottemburg, } \\
1775)\end{array}$ & $36,146,179$ & \\
\hline 84. & Brintesia circe (Fabricius, 1775) & $34,41,99,120,129,188,209,278$ & MARČEC 2008 \\
\hline 85. & $\begin{array}{l}\text { Coenonympha arcania (Lin- } \\
\text { naeus, 1761) }\end{array}$ & $\begin{array}{l}8,11,23,29,30,31,34,36,41,68,108, \\
110,113,120,129,134,143,148,222, \\
224,225,249\end{array}$ & MARČEC 2008 \\
\hline 86. & $\begin{array}{l}\text { Coenonympha glycerion } \\
\text { (Borkhausen, 1788) }\end{array}$ & $\begin{array}{l}1,6,7,8,10,11,15,19,20,23,25,26,34, \\
36,39,40,44,47,49,50,57,59,67,70 \\
78,87,90,93,98,100,103,107,117,120, \\
124,126,128,129,134,137,141,143, \\
153,157,161,167,169,198,202,220 \\
221,224,231,236,237,238,239,241, \\
243,244,249,257,260,264,270,273, \\
275,277,278,290,291\end{array}$ & MARČEC 2008 \\
\hline 87. & $\begin{array}{l}\text { Coenonympha pamphilus } \\
\text { (Linnaeus, 1758) }\end{array}$ & $\begin{array}{l}1,3,4,6,7,8,10,11,12,14,15,17,19,20, \\
22,23,26,27,29,30,34,36,38,39,40,44, \\
45,47,48,50,51,53,57,59,61,67,70,75, \\
76,77,78,83,84,85,87,90,93,97,103, \\
106,107,111,113,119,120,121,124,126, \\
129,130,132,134,137,141,143,144,147, \\
148,153,154,156,160,161,167,169,170, \\
171,173,176,177,186,187,189,190,196, \\
198,200,202,213,220,225,233,235,236, \\
239,240,242,243,244,246,247,249,250, \\
252,254,256,257,258,259,260,262,270, \\
272,275,276,277,280,283,287,290,291\end{array}$ & $\begin{array}{l}\text { ABAFI-Aigner 1910, } \\
\text { MARČEC } 2008\end{array}$ \\
\hline 88. & Erebia aethiops (Esper, 1777) & $\begin{array}{l}33,34,45,49,103,184,197,215,217, \\
223,233,278\end{array}$ & MARČEC 2008 \\
\hline 89. & $\begin{array}{l}\text { Euphydryas aurinia (Rottem- } \\
\text { burg, 1775) }\end{array}$ & $76,78,143,144,200$ & \\
\hline 90. & $\begin{array}{l}\text { Euphydryas maturna (Linnaeus, } \\
1758 \text { ) }\end{array}$ & & Gussich 1917 \\
\hline 91. & $\begin{array}{l}\text { Hipparchia (Hipparchia) fagi } \\
\text { (Scopoli, 1763) }\end{array}$ & $129,144,190$ & MARČEC 2008 \\
\hline
\end{tabular}




\begin{tabular}{|c|c|c|c|}
\hline No & List of species & Locality number & Literature \\
\hline 92. & $\begin{array}{l}\text { Hipparchia (Hipparchia)semele } \\
\text { (Linnaeus, 1758) }\end{array}$ & & MARČEC 2008 \\
\hline 93. & $\begin{array}{l}\text { Issoria (Issoria) lathonia } \\
\text { (Linnaeus, 1758) }\end{array}$ & $\begin{array}{l}24,29,33,34,37,41,45,49,128,134, \\
143,172,179,189,211,219,222,225, \\
276,282,289,292\end{array}$ & MarČEC 2008 \\
\hline 94. & $\begin{array}{l}\text { Lasiommata maera (Linnaeus, } \\
\text { 1758) }\end{array}$ & 41 & MARČEC 2008 \\
\hline 95. & $\begin{array}{l}\text { Lasiommata megera (Linnaeus, } \\
1767 \text { ) }\end{array}$ & $\begin{array}{l}19,41,46,83,109,111,120,170,190, \\
210,217,243,276,281\end{array}$ & $\begin{array}{l}\text { AbAfi-Aigner 1910, } \\
\text { MARČEC 2008, } \\
\text { MLADINOV } 1973\end{array}$ \\
\hline 96. & $\begin{array}{l}\text { Limenitis camilla (Linnaeus, } \\
1764 \text { ) }\end{array}$ & $34,215,217,252,279$ & $\begin{array}{l}\text { ABAFI-AignER 1910, } \\
\text { MARČEC } 2008\end{array}$ \\
\hline 97. & $\begin{array}{l}\text { Limenitis reducta Staudinger, } \\
1901\end{array}$ & $\begin{array}{l}29,30,33,34,41,45,49,50,79,182,192 \\
210,215,252\end{array}$ & MaRČEC 2008 \\
\hline 98. & Lopinga achine (Scopoli, 1763) & $211,217,234,266,278,279$ & $\begin{array}{l}\text { LoRкоvić 2009, } \\
\text { ŠAšIĆ \& MiнOCI } 2007\end{array}$ \\
\hline 99. & $\begin{array}{l}\text { Maniola jurtina (Linnaeus, } \\
\text { 1758) }\end{array}$ & $\begin{array}{l}1,3,4,5,6,9,10,11,15,18,19,20,21, \\
22,23,25,27,28,29,30,31,32,33,34, \\
35,37,38,39,40,41,42,44,45,49,50, \\
51,52,53,57,58,59,60,61,62,67,68, \\
69,70,72,77,78,81,82,84,88,90,91, \\
94,98,99,100,102,103,104,107,108, \\
110,111,112,113,116,117,118,120, \\
123,124,128,129,131,132,133,135, \\
136,137,139,140,141,144,146,148, \\
149,151,154,155,157,159,160,161, \\
164,165,166,167,168,169,170,173, \\
175,178,179,182,184,188,189,190, \\
192,194,196,197,199,202,204,205, \\
209,210,211,213,215,217,219,222, \\
224,225,227,233,235,236,237,238, \\
239,240,242,243,244,247,248,249, \\
252,256,258,259,260,262,263,268 \\
269,270,271,273,274,275,276,277, \\
278,279,282,283,287,290,291\end{array}$ & $\begin{array}{l}\text { AbAfi-Aigner 1910, } \\
\text { MARČEC } 2008\end{array}$ \\
\hline 100. & $\begin{array}{l}\text { Melanargia galathea (Linnaeus, } \\
1758 \text { ) }\end{array}$ & $\begin{array}{l}4,5,9,10,23,27,28,29,31,33,34,36, \\
37,45,49,72,77,81,84,91,94,98,99, \\
103,104,108,112,113,116,117,120 \\
124,126,129,131,134,136,139,141 \\
143,148,149,150,151,155,158,164, \\
166,168,173,175,176,178,179,186, \\
189,199,205,211,219,222,225,229 \\
239,243,252,256,258,264,270,271 \\
272,274,276,278,279,280,283,287\end{array}$ & $\begin{array}{l}\text { AbAFi-Aigner 1910, } \\
\text { MARČEC } 2008\end{array}$ \\
\hline
\end{tabular}




\begin{tabular}{|c|c|c|c|}
\hline No & List of species & Locality number & Literature \\
\hline 101. & $\begin{array}{l}\text { Melitaea athalia (Rottemburg, } \\
1775 \text { ) }\end{array}$ & $\begin{array}{l}1,7,8,11,12,14,15,19,20,23,26,27, \\
34,36,37,38,39,41,44,45,47,50,57, \\
58,59,70,78,83,85,87,90,93,103,107, \\
111,112,113,117,120,126,129,131, \\
134,137,143,144,146,147,153,154, \\
161,164,166,169,171,177,178,179, \\
181,186,190,192,198,202,207,210, \\
211,216,226,233,235,238,239,241, \\
243,247,249,256,257,260,262,264, \\
265,269,270,273,275,277,278,279, \\
283,291\end{array}$ & $\begin{array}{l}\text { AbAfi-Aigner 1910, } \\
\text { Marčec 2008, } \\
\text { Koren \& Jugovic } \\
2012\end{array}$ \\
\hline 102. & Melitaea aurelia Nickerl, 1850 & $\begin{array}{l}34,49,83,85,103,108,120,129,151 \\
168,225,275\end{array}$ & $\begin{array}{l}\text { MARČEC 2008, KorEN } \\
\text { \& JugOVIC } 2012\end{array}$ \\
\hline 103. & $\begin{array}{l}\text { Melitaea britomartis Assmann, } \\
1847\end{array}$ & $26,78,153,200$ & $\begin{array}{l}\text { Koren \& Jugovic } \\
2012\end{array}$ \\
\hline 104. & $\begin{array}{l}\text { Melitaea cinxia (Linnaeus, } \\
1758 \text { ) }\end{array}$ & $\begin{array}{l}7,70,78,83,85,129,142,143,153,200, \\
220,257\end{array}$ & $\begin{array}{l}\text { AbAfi-Aigner 1910, } \\
\text { MARČEc } 2008\end{array}$ \\
\hline 105. & Melitaea diamina (Lang, 1789) & $11,243,291$ & $\begin{array}{l}\text { AbAFi-Aigner 1910, } \\
\text { MARČEc } 2008\end{array}$ \\
\hline 106. & Melitaea didyma (Esper, 1778) & $\begin{array}{l}1,7,8,15,19,25,26,29,30,34,38,47 \\
49,50,61,78,91,99,120,124,126,129 \\
134,143,171,178,186,189,220,238 \\
239,243,256,287\end{array}$ & MARČEC 2008 \\
\hline 107. & Melitaea ornata Christoph, 1893 & 143 & Koren \& ŠTIH 2013 \\
\hline 108. & $\begin{array}{l}\text { Melitaea phoebe (Denis \& } \\
\text { Schiffermüller, 1775) }\end{array}$ & $\begin{array}{l}5,7,14,15,19,25,26,29,30,34,45,49 \\
50,78,83,85,103,108,129,134,143 \\
147,190,200,220,239,243,247,257 \\
270,275,281,287\end{array}$ & Abafi-Aigner 1910 \\
\hline 109. & $\begin{array}{l}\text { Melitaea trivia (Denis \& } \\
\text { Schiffermüller, 1775) }\end{array}$ & $29,34,49,124,143,178$ & Авafi-Aigner 1910 \\
\hline 110. & Minois dryas (Scopoli, 1763) & $\begin{array}{l}6,15,28,29,30,34,45,49,51,103,120 \\
126,128,143,157,225,243,262,263 \\
271,278,287\end{array}$ & MARČEc 2008 \\
\hline 111. & Neptis rivularis (Scopoli, 1763) & $37,49,64,68,108,192,194,215$ & $\begin{array}{l}\text { Abafi-Aigner 1910, } \\
\text { MARČEC } 2008\end{array}$ \\
\hline 112. & Neptis sappho (Pallas, 1771) & $\begin{array}{l}6,7,9,19,29,30,31,33,34,41,45,46, \\
49,50,55,66,75,79,80,89,90,95,97, \\
103,108,120,127,134,135,142,143 \\
144,149,154,163,164,179,181,182, \\
183,184,188,192,196,197,209,213 \\
215,216,217,229,233,234,235,242, \\
243,252,262,263,266,269,271,279, \\
282,284,287\end{array}$ & $\begin{array}{l}\text { AbAfi-Aigner 1910, } \\
\text { MarČEc } 2008\end{array}$ \\
\hline 113. & $\begin{array}{l}\text { Nymphalis antiopa (Linnaeus, } \\
1758 \text { ) }\end{array}$ & $\begin{array}{l}29,34,105,108,135,139,174,180,185, \\
217,218\end{array}$ & $\begin{array}{l}\text { AbAfi-Aigner 1910, } \\
\text { MARČEC } 2008\end{array}$ \\
\hline 114. & $\begin{array}{l}\text { Nymphalis polychloros } \\
\text { (Linnaeus, 1758) }\end{array}$ & $\begin{array}{l}\text { 29, 34, 105, 108, 139, 142, 180, 192, 201, } \\
214,217\end{array}$ & $\begin{array}{l}\text { AbAfi-Aigner 1910, } \\
\text { MarČEc } 2008\end{array}$ \\
\hline 115. & $\begin{array}{l}\text { Pararge aegeria (Linnaeus, } \\
1758 \text { ) }\end{array}$ & $\begin{array}{l}\text { 7, 33, 34, 41, 49, 64, 71, 73, 78, 81, 103, } \\
105,108,123,174,192,197,225,234,238\end{array}$ & MARČEC 2008 \\
\hline
\end{tabular}




\begin{tabular}{|c|c|c|c|}
\hline No & List of species & Locality number & Literature \\
\hline 116. & $\begin{array}{l}\text { Polygonia c-album (Linnaeus, } \\
1758 \text { ) }\end{array}$ & $\begin{array}{l}6,15,23,24,29,30,31,33,34,40,41,45, \\
49,50,52,54,64,79,90,98,102,105, \\
108,110,113,120,123,125,135,139, \\
142,144,146,148,159,160,174,180, \\
184,185,188,192,194,197,199,201, \\
204,210,215,217,219,222,224,225, \\
226,234,243,255,259,269,273,279, \\
282,286,289\end{array}$ & $\begin{array}{l}\text { ABAFI-AIGNER 1910, } \\
\text { MARČEC } 2008\end{array}$ \\
\hline 117. & $\begin{array}{l}\text { Pyronia (Pyronia) tithonus } \\
\text { (Linnaeus, 1767) }\end{array}$ & 78 & $\begin{array}{l}\text { ABAFI-Aigner 1910, } \\
\text { MARČEC } 2008\end{array}$ \\
\hline 118. & $\begin{array}{l}\text { Vanessa atalanta (Linnaeus, } \\
1758 \text { ) }\end{array}$ & $\begin{array}{l}2,8,9,29,32,33,34,37,40,41,43,44 \\
45,49,50,57,77,78,79,82,97,103,107 \\
108,120,122,123,129,133,135,139 \\
142,143,144,148,159,182,184,188 \\
192,196,202,207,209,211,214,215 \\
219,222,223,225,239,243,244,248 \\
249,252,263,275,284\end{array}$ & $\begin{array}{l}\text { ABAFI-AIGNER 1910, } \\
\text { MARČEC } 2008\end{array}$ \\
\hline 119. & Vanessa cardui (Linnaeus, 1758) & $\begin{array}{l}1,10,12,15,36,38,39,40,44,67,70,90 \\
97,98,99,109,110,112,113,120,129 \\
143,217,219,225,249,278\end{array}$ & $\begin{array}{l}\text { ABAFI-AIGNER 1910, } \\
\text { MARČEC } 2008\end{array}$ \\
\hline
\end{tabular}

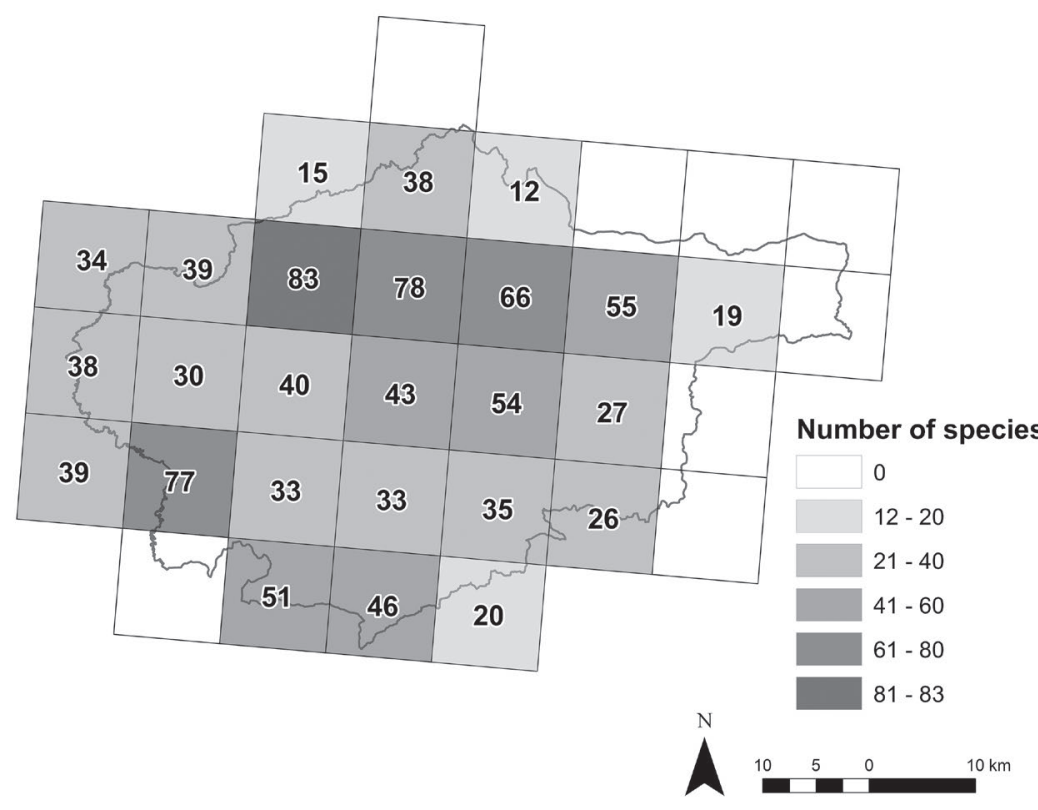

Fig. 2. EEA $10 \times 10 \mathrm{~km}$ reference grid with the number of recorded species within each square. 


\section{DISCUSSION}

In the historically extensively managed agricultural landscape of Hrvatsko zagorje with small parcels of mosaic and diverse land use and heterogeneous habitats, changes in agricultural policy and globalisation led to the decline and abandonment of pastures and meadows, with the consequence of declining butterfly diversity. Today, suitable habitats in lowland and hilly areas are dotted between arable land and forest fragments on the hills. Big areas of wet meadows are urbanised or overgrown by invasive alien plant species.

Habitat generalists like Pieris rapae (Linnaeus, 1758), Pieris napi (Linnaeus, 1758), Leptidea sinapis (Linnaeus, 1758), Melitaea athalia (Rottemburg, 1775), Gonepteryx rhamni (Linnaeus, 1758), Coenonympha pamphilus (Linnaeus, 1758), Lysandra icarus (Rottemburg, 1775) and Maniola jurtina (Linnaeus, 1758) are still common and widespread throughout the region. On the other hand, habitat specialists are usually very local and present only on suitable habitat types, which are also usually scarce and small.

Dry grasslands are one of the most endangered habitats in the region, as the only preserved patches of grasslands in the area remained in mountainous areas. They are usually located on steep or not easily accessible localities and are now abandoned and overgrown with shrubs and small trees. The best-preserved dry grasslands in the area are at the locality Plat on the southern slope of Mt. Strahinjščica. They were revitalized several years ago, and are now regularly mowed late in the season once a year, to stop the succession, which is the main cause of degradation of dry grasslands. There are several areas in the region that urgently need actions for preventing loss of grasslands, like Mt. Ivanščica, Zelenjak and on other preserved meadows in the western part of the region, near the Sutla River. Due to lack of suitable habitats dry grassland specialists like Plebejus spp., Polyommatus daphnis (Denis \& Schiffermüller, 1775), Pyrgus armoricanus (Oberthür, 1910), Spialia sertorius (Hoffmannsegg, 1804), Carcharodus floccifera (Zeller, 1847) or even Carcharodus alceae (Esper, $1780)$ are generally very rare in the region.

Polyommatus thersites (Cantener, 1834) is another rare and a local species in Hrvatsko zagorje but also generally in Croatia, categorized as Near Threatened (ŠAšić et al., 2015). This species inhabits dry grasslands on which its host plant, Onobrychis viciifolia Scop., grows. In Hrvatsko zagorje we recorded this species on small grassland patches on Mt. Strahinjščica, Mt. Ivančica and Risvica and Cesar hill. On similar habitats Phengaris alcon rebeli (Dennis \& Schiffermüller, 1775) and Polyommatus daphnis were found, also in very small numbers. All three species are endangered due to lack of management on grasslands being overgrown with shrubs.

Wet grasslands are found along watercourses and in areas with limited drainage in valleys. Several interesting species have been found there including a wet grassland specialist, Boloria selene (Dennis \& Schiffermüller, 1775), which was recorded only once with a single specimen. While several historical records exist for this species in northern Croatia, it seems that it is becoming rare in Hrvatsko zagorje as the majority of wet grasslands are abandoned and declining. Similarly, in the neighbouring Slovenian region, Haloze, the species was recorded at only two of 67 surveyed localities (VerovniK, 2003). This species is not included in the Red Book of butterflies of Croatia (ŠAšić et al., 2015) but with the start of monitoring activities, we will be able to determine changes in population trends. Additionally, wet grassland species included in the Habitats Directive Annexes, Euphydryas aurinia (Rottemburg. 1775) and Lycaena dispar (Haworth, 1802) are present in these habitats and are included in the Natura 2000 network of nature protection areas of the European Union.

An additional Habitats Directive species, Phengaris teleius, has been observed on grasslands along the Bednja River. Its habitats are slowly overgrowing by shrubs and invasive plant species and urgent conservation actions are needed to prevent the disappearance of the species from Hrvatsko zagorje.

Species inhabiting forest clearings, forest edges and light woodlands are rarely observed. The same is true for Hipparchia species, with only three records of $H$. fagi, and none of $H$. semele, which is more common on karstic areas. Only a single specimen of $H$. fagi was observed in the region. We were expecting to find populations in woodlands on Mt. Ivanščica and Mt. Strahinjščica, but without success, despite many field observations. Lorković (2009) had already stated that the species was rare in lowland hill forests. Similarly, L. achine (Scopoli, 1763) has been observed only on Mt. Ivanščica with only a dozen observed specimens. The consecutive visits to the same locality during the last couple of years have yielded no further observation of this species, which may indicate it has become extinct or that the numbers have dropped to levels below the detectability threshold. 
In contrast with the past, forests are becoming increasingly dense and not used or maintained in the same way as 40 years ago, when the edges were regularly cleaned, leaf litter was partly used in livestock keeping, and the clearings and forest edges were full of flowers. Today there is a lot less undergrowth and the forest edges are not maintained, being overgrown by shrubs, Rubus species and invasive plants or they are cleaned with heavy machinery, which destroys remaining plants and insects in the middle of the season. Therefore, many forest species are also declining.

Erebia aethiops (Esper, 1777) is the only member of the genus Erebia in northern Croatia. The presence of this species on Mt. Ivanščica was already published (Lorкović, 2009) but the species was additionally discovered on Mt. Strahinjščica, Mt. Ivanščica and Risvica and Cesar hill. On the neighbouring Mt. Medvednica near Zagreb, this species was not recorded during the recent intensive survey (Koren, unpublished), indicating possible changes in the butterfly diversity. Further studies of the population of this species in northern Croatia are needed in order to access its status.

An interesting species that was observed only twice in the region is Pyronia tithonus (Linnaeus, 1767). Historically it was known from many regions in mainland Croatia, but with limited number of records (JAKšść, 1988). The species is common in the Mediterranean region (e.g. Istria), but in the continental part of the country it is very localized. It usually inhabits forest edge habitats like shrubs, field edges and hedgerows. Additional surveys of this species are needed, in order to access its distribution and status in the region.

Six species have not been found during our nine years of study. One is the most endangered European species Colias myrmidone (Esper, 1781), which is already extinct from several countries (MARHoul \& DoleK, 2012). In the past it was present in the surroundings of Krapina (ABAFI-Aigner 1910). During recent surveys in nearby Slovenia it was not found as either (VERovNIK, 2003). The last record of the species from Croatia is from the 1990s (KRČMAR et al., 1996), which is similar to the situation in Slovenia, where it is presumed to be extinct (PredovniK \& VerovniK, 2004).

Another formerly common species which we have not found is Aporia crataegi (Linnaeus, 1758). In the past, it was a widely distributed species in Croatia (Lorković, 2009), also in the WE part. BRUSINA (1889) reports an interesting observation from his train ride from Zagreb to Varaždin: "in the places where the land was wet, or at dunghills, hundreds of butterflies could be seen, one close to another drinking from the surface, which from the distance looked like a big white sheet". He also mentions that in a nearby region, Kutinsko-Moslovačka County, money was offered for 100 caught butterflies, and during the first day, 7000 adults were caught. Nowadays, such large populations are a rarity especially in the northern part of the country. Despite natural fluctuations in numbers, it seems that the species is slowly disappearing from the northern part of Croatia. However, the statement should be confirmed with long-term monitoring. At present, its IUCN Red List status at the European scale is Least Concern, but it has been reported as regionally extinct in the Czech Republic, the Netherlands and the United Kingdom (van SwaAy et al., 2010).

Also, we could not confirm the Natura 2000 woodland species, Euphydryas maturna (Linnaeus, 1758). This species is very localized and present only in the northern part of the country (LoRкоvić, 2009). We visited several potential habitats for this species, and several of them like Lobor valley or the northern part of Mt. Ivanščica seemed very suitable as habitat is similar to the species' habitat in other parts of the country. E. maturna will be one of the target species for future surveys as it is present in Slovenia close to the state border (Verovnik et al., 2012). Additional field surveys should be carried out in order to confirm historical finding (LoRKović, 1993) of another Natura 2000 species Leptidea morsei (Fenton, 1882) in deciduous woodland at the base of Mt. Ivanščica

In addition, Argynnis niobe, a species observed to be in strong decline in Europe, was not found during recent surveys. Recent studies show species dependence on very large areas of potential larval habitats with Viola spp. and Plantago (SALZ \& FARTMANn, 2009), which might be a problem in the mosaic landscape of Hrvatsko zagorje because most of the meadows and forest edges are becoming abandoned.

Whereas the majority of butterfly species in the region are declining in abundance due to habitat loss and habitat changes, Pieris mannii (Mayer, 1851) seems to be expanding its range towards the north. Lorкоvić (2009) stated that the species is rare but present on rocky areas in continental Croatia. Verovnik (2003) reports the first findings of the species in Haloze across the border and we found this species more often in Hrvatsko zagorje in recent years as well as across the border in Kozjanski Park in Slovenia. In addition, Argynnis pandora (Denis \& Schiffermüller, 1775) is more often seen in the region, most probably due to climate change and global warming. In Slovenia, there are no known records of this species more northerly than Hrvatsko zagorje (VerovNIK, 2003). 
In a wider context, Hrvatsko zagorje preserves a more diverse butterfly fauna than the neighbouring region of Haloze in Slovenia, with a reported 96 species from 67 localities (VEROVNIK, 2003). However, looking at the situation of the remaining preserved flowering grassland and other valuable butterfly habitats, the future is not very optimistic. Small-scale farming is already disappearing as farms cannot survive and compete with globalisation. Therefore, more and more meadows are abandoned, turned into fields or too intensively managed. Forest edges, hedges and wet meadows are overgrowing with invasive alien plants. Therefore, suitable habitats for butterflies that are habitat specialists are increasingly difficult to find, and the distances between them are increasing with the disappearance of habitat patches in between. In the near future this will probably lead to local extinctions of some species, especially dry grassland specialists like $P$. thersites or $P$. daphnis. To preserve this valuable diversity in the region, renaturation of remaining grassland would be necessary and urgent. In the long term, this can work only in cooperation with local farmers, to enable them economic survival using extensive agriculture. With increasing globalisation and pressure on production processes from the global market the future does not look very optimistic even with more focused subsidies. To preserve valuable habitats in the region a joint cross-border approach with Kozjanski park and Haloze region is proposed to connect refugial habitats with potential dispersal corridors to enable sufficient gene flow between neighbouring populations of endangered species.

\section{CONCLUSIONS}

This contribution to the butterfly fauna is one of only a few extensive surveys of larger areas of Croatia, with the exception of Podravina region (KRANJčEv, 1985) and the island of Krk (HABELER, 2008). With the combination of random surveys and targeted visits to the EEA $10 \times 10 \mathrm{~km}$ grids, we were able to map the general butterfly biodiversity of the region. Prior to our survey the butterfly fauna of Hrvatsko Zagorje region was one of the least studied regions in Croatia, with a very limited number of literature records. During our survey, we could not record any significant expansions in the known species ranges; however, our data fill an existing gap in the known distribution of butterflies of Croatia. We still expect to reconfirm some species in the future which are known from the literature; however, no major increase in species richness is expected. The region Hrvatsko Zagorje may now be considered as one of the best studied regions in Croatia.

The largest butterfly biodiversity in the region can be found on the hills or in the mountains with preserved and diverse natural habitats. Some species historically inhabiting the region became very rare in the last century, or have possibly disappeared from the region. The most endangered habitats are grasslands and consequently, the most endangered butterflies are grassland specialists. Most of the remaining grasslands are abandoned and overgrown with shrubs and even trees. Wet grasslands are mostly covered with invasive plant species as they are not mowed, or at least, not regularly. For the long-term preservation of remaining grasslands, appropriate conservation actions and correct habitat management are needed.

As the Slovenian side of the border is also well surveyed (Verovnik, 2003), this result could be important in order to start joint conservation efforts to preserve the butterfly diversity on a broader scale. We would also encourage additional surveys and publications from the neighbouring region to gain a more comprehensive picture about the butterfly diversity of Croatia.

\section{ACKNOWLEDGMENTS}

The authors would like to thank a large number of individuals who contributed to this paper, either by data, or by their company during the field trips, including Mladen Zadravec, Maja Bjelić, and Marija Radić. Part of the study was financed within the project "Research into moth fauna in the ecological network Natura 2000 Strahinjščica and Ivanščica, Krapina-Zagorje county" financed by the Public Institution for the Management of Protected Areas in Krapina-Zagorje county. 


\section{REFERENCES}

Abafi-Aigner, L., 1910: Adaléka Magyar Tengermellék, Horvátország és Dalmáczia lepkefaunájához. Rovartani Lapok 17, 55-57, 71-105.

BrusinA, S., 1889: O šteti koju je u Hrvatskom Zagorju prouzrocio leptir Aporia crataegi L. Glasnik Hrvatskog naravoslovnog društva 3, 231.

CRKvenČić, I., 1956: Hrvatsko zagorje kao emigraciono žarište, Geografski glasnik, 18, 33-46.

Dincă, V., Lukhtanov, V. A.; Talavera, G. \&Vila, R., 2011: Unexpected layers of cryptic diversity in wood white Leptidea butterflies. Nature Communications 2, 324.

de Jong, Y., Verbeek, M., Michelsen, V., Bjørn, P. de P., Los, W., Steeman, F., Bailly, N., Basire, C., Chylarecki, P., Stloukal, E., Hagedorn, G., Wetzel, F., Glöckler, F., Kroupa, A., Korb, G., Hoffmann, A., Häuser, C., Kohlbecker, A., Müller, A., Güntsch, A., Stoev, P. \& Penev, L., 2014: Fauna Europaea - all European animal species on the web. Biodiversity Data Journal 2, 1-35.

Gušić, B., 1917: Ein Beitrag zur Schmetterlingsfauna Kroatiens. Glasnik Hrvatskog prirodoslovnoga društva 28-29, 209-225.

Habeler H., 2008[2003]: Die Schmetterlinge der Adria-Insel Krk - Eine ökofaunistische Studie. Esperiana - Buchreihe zur Entomologie 1-221.

JAKšić, P., 1988: Privremene karte rasprostranjenosti dnevnih leptira Jugoslavije. Jugoslavensko entomološko društvo. Posebna izdanja 1, 214.

Koren, T. \& J. Jugovic, 2012: New data on the presence of three similar species of the genus Melitaea: M. athalia, M. aurelia and M. britomartis (Lepidoptera: Nymphalidae) in the North-Western Balkans. Annales Series Historia Naturalis 22, 25-34.

Koren, T. \& G. Letić, 2014: Butterfly fauna (Lepidoptera: Rhopalocera) of Donji Emovci, Požega, Croatia. Natura Sloveniae 16, 5-16.

Koren, T., Krčmar, S. \& Dretvić, T., 2012: Contribution to the knowledge of butterflies (Lepidoptera: Rhopalocera) of Bansko brdo. Entomologia Croatica 16, 41-60.

Koren, T., Zadravec, M., ŠTih, A. \& D. Hlavati, 2013: Butterfly fauna (Hesperoidea \& Papilionoidea) of a rural part of Zagreb City, Croatia. Natura Croatica 22, 253-264.

Koren, T. \& LAuš, B., 2013: Dinara Massif - a new hotspot for the butterfly (Papilionoidea) diversity of the Dinaric Arc. Nota Lepidopterol. 36(2), 109-126.

Koren, T. \& Šтін, A., 2013: On the occurrence of Eastern knapweed fritillary, Melitaea ornata (Lepidoptera: Nymphalidae) in Croatia. Phegea 41(3), 63-66.

Koren, T., Buelić, M., ŠKuljević, P. \& Gomboc, S., 2014: Contribution to the knowledge of the butterfly fauna (Insecta: Lepidoptera) of the Adriatic island Hvar, Croatia. Acta Entomologica Slovenica 22(1), 29-44.

Koren, T., Vukotić, K. \& Verovnik, R., 2015a: Butterflies (Lepidoptera: Papilionoidea \& Hesperioidea) of the Croatian islands: new surveys of Vir, Murter, Čiovo and Šolta. Entomol. Gaz. 66, 187-197.

Koren, T., Črne, M., Pavliha, G. \& Trkov, D., 2015b: Mountain Poštak, a new hotspot for the Lepidoptera of Croatia (Lepidoptera: Rhopalocera). SHILAP Revta. Lepidopterol. 43(169), 145-155.

Kovačić, M., 2010: Geological curiosities of Krapina-Zagorje County, Institute of Mineralogy and Petrology, Department of Geology, Faculty of Science, University of Zagreb, 1-30.

KRANJČEV, R., 1985: Odnos faune makrolepidoptera prema prirodnim i antropogenim staništima Podravine i podravskih pijesaka (I). Podravski zbornik 11, 200-226.

KRČMAR, S., 2002: Data on the Butterfly fauna of the Croatian part of Baranja (Lepidoptera Rhopalocera). Bulletin de la Societe Royale Belge d Entomologie 138, 151-153.

Kučinić, M., Minoci, I., Tvrtković, N., Šašić, M., Bojanić, D., Joković, S., Mazija, M. \& Popijač, A., 2010 : Butterfly Diversity (Insecta: Lepidoptera, Rhopalocera) of the Island of Mljet, Croatia. Proc. Symp. Branimir Gušić Days, Mljet, pp. 111-125.

Kučinić, M., Randić, M., Mihoci, I., Koren, T., Mrnjavčić Vojvoda, A., Lauš, B. \& Burić, I., 2014: Contribution to Knowledge of the Distribution of the Geranium Bronze Caycreus marshalii (Butler, 1898) (Lepidoptera, Lycaenidae) in Croatia with Note on Ecology and Ethology. Entomologia Croatica 18(1-2), 49-57.

LoRKović, Z., 1993: Ecological association of Leptidea morsei major Grund 1905 (Lepidoptera, Pieridae) with the oak forest Lathyreto - Quercetum petraeae Hr-t 1957 in Croatia. Period. biol. 95(4), 455-457.

Lorković, Z., 2009: The Rhopalocera fauna of Croatia with special respect to the fauna of Plitvice Lakes. Entomol. Croat. 13, 15-78. 
Marčec, V., 2008: Dnevni leptiri (Insecta, Rhopalocera) zbirke Franje Košćeca Gradskog muzeja Varaždin i komparacija s današnjim stanjem istraživanog područja. Franjo Košćec i njegovo djelo : 1882.-1968. : zbornik radova sa znanstvenog skupa održanog 13. i 14. studenoga 2008. u Varaždinu / [editors M. Šicel, B. Spevec].

Marhoul, P. \& M. Dolek, 2012: Action Plan for the Conservation of the Danube Clouded Yellow Colias myrmidone in the European Union. European Commission

Mladinov, L., 1973: Lepidoptera (Rhopalocera) zbirki Hrvatskog narodnog zoološkog muzeja u Zagrebu. Hrvatski narodni zoološki muzej Zagreb, 7, 36 pp.

Mladinov, L., 1975: Lepidoptera- Hesperiidae (Rhopalocera) u zbirki Hrvatskog narodnog zooloskog muzeja u Zagrebu. Hrvatski narodni zoološki muzej Zagreb, 8.

NJEGAČ, D., 1999: Funcionalna diferencijacija naselja I centralnomjesna organizacija Hrvatskog zagorja, Hrvatski geografski glasnik, 61, 25-36.

Predovnik Z. \& Verovnik, R., 2004: New records of rare pierids (Lepidoiptera: Pieridae) in Slovenia. Natura Sloveniae 6(2), 39-47

SAlz, A. \& FARTMANN, T., 2009: Coastal dunes as important strongholds for the survival of the rare Niobe fritillary (Argynnis niobe). Journal of. Insect Conseration 13, 643-654.

SteIner, S., 1916: Ein kleiner Beitrag zur Lepidopteren-Fauna von Kroatien und Slavonien. Intern. Entom. Zeitschr., Guben, 2, 106.

ŠAšIĆ, M. \& MinocI, I., 2007: New findings of the wood brown Lopinga achine (Scopoli, 1763) (Lepidoptera: Nymphalidae: Satyrinae) in Croatia. Entomologia Croatica 11(1-2), 63-67.

ŠAšIĆ, M. \& Minoci, I., 2011: Annotated checklist of Croatian butterflies with vernacular names. Natura Croatica 20(2), 425-436.

ŠAšıć, M., MıHoci, I., Kučınıć, M., 2015. Crvena knjiga danjih leptira Hrvatske. Ministarstvo zaštite okoliša i prirode, Državni zavod za zaštitu prirode, Hrvatski prirodoslovni muzej, Zagreb.

ŠEgota, T. \& Filıpčıć, A., 2003: Köppenova podjela klima i hrvatsko nazivlje. Geoadria 8/1, 17-37.

Tolman, T. \& Lewington, R., 2008: Butterflies of Britain \& Europe. Harper Collins Publishers, London.

Tvrtković, N., Minoci, I. \& ŠAšić, M. 2011: Colias Caucasica Balcanica Rebel, 1901 (Pieridae) in Croatia - the Most Western Distribution Point. Natura Croatica 20(2), 375-85.

Tvrtković, N., M. Šašić, M. Vuković, I. Mihoci \& BJelić, M., 2012: Review of the butterfly fauna (Hesperioidea \& Papilionoidea) of the Dinara mountain range. Natura Croatica 21(2), 471-481.

Van Swaay, C.A.M., Cuttelod, A., Collins, S., Maes, D., Munguira, L.M., Šašić, M., Settele, J., VerovNik, R., Verstrael, T., Warren, M., Wiemers, M., Wynhoff, I., 2010: European Red List of Butterflies, Luxembourg: Publications Office of the European Union. 47 pp.

Verovnik, R., 2003: The Distribution of Butterflies (Lepidoptera: Rhopalocera) in Haloze, East Slovenia. Natura Sloveniae 5(2), 31-46.

VerovniK, R., 2011: Butterflies (Lepidoptera: Rhopalocera) of the Croatian islands: an update on published records and new surveys of Pašman and Ugljan. Entomol. Gaz. 62, 251-263.

Verovnik, R., Rebeušek, F. \& Jež, M., 2012: Atlas of butterflies (Lepidoptera: Rhopalocera) of Slovenia. Center za kartografijo favne in flore, Miklavž na Dravskem polju, $456 \mathrm{pp}$.

VučEtić, V., 2007: Funkcionalna i prosotrna obilježja povijesnih gradskih naselja Zagorja. Povijest, baština i kultura Krapinsko-zagorske županije, 40-53.

Withrington, D. \& Verovnik, R., 2008: Butterflies (Rhopalocera) of the Croatian islands. Entomol. Gaz. 59, 3-25. 


\title{
SAŽETAK
}

\section{Prilog poznavanju faune danjih leptira (Lepidoptera: Papilionoidea) Hrvatskog zagorja, Hrvatska}

\author{
T. Koren, B. Lauš, M. Šašić, I. Mihoci, A. Štih, P. Bralić \& S. Gomboc
}

Područje Hrvatskog zagorja jedno je od najneistraženijih područja u Hrvatskoj u pogledu raznolikosti danjih leptira, s tek ograničenim brojem literaturnih nalaza, većinom starijih od 100 godina. Naše istraživanje ove regije trajalo je devet godina, od 2008. pa do 2016. godine, prilikom čega smo posjetili 292 lokacije. Kao podlogu za kartiranje koristili smo EEA 10x10 kilometarsku mrežu, koju smo prvih godina popunjavali nesustavno, a 2016. godine ciljano smo kartirali i posjećivali slabije istražene ili neistražene lokacije. Ukupno smo zabilježili 112 vrste danjih leptira, a pregledom literature zabilježili smo dodatnih šest vrsta, što zajedno čini 118 vrsta ili $60 \%$ faune danjih leptira Hrvatske. Najveća raznolikost leptira zabilježena je na planinama Ivanjščici i Strahinjščici te u dolini rijeke Sutle. Tijekom istraživanja primijećeno je da se vrste koje su stanišni generalisti mogu susresti gotovo na svim lokacijama, dok su vrste vezane uz točno određene stanišne tipove, odnosno stanišni specijalisti, vrlo lokalne i uglavnom malobrojne. Zabilježili smo i nekoliko rijetkih i ugroženih vrsta, ponajviše travnjačkih specijalista poput Phengaris teleius, Ph. alcon., Polyommatus thersites, Euphydryas aurinia i Zerynthia polyxena čija su staništa u opadanju zbog promjene u korištenju travnjaka poput zapuštanja ili rjeđe, pojačanog korištenja. Populacija vrste Lycaena dispar je još uvijek lokalno mnogobrojna, no i njena se staništa ubrzano zarastaju od strane invazivnih biljaka. Regija Hrvatskog zagorja bogatija je vrstama nego susjedna regija Haloze u Sloveniji (VerovniK, 2003), no primijećeni su negativni trendovi u nestanku staništa. Promjene u načinu gospodarenja zemljištem, prvenstveno napuštanje tradicionalnog stočarstva kao i poljoprivrede na malim parcelama, dovelo je do zarastanja i nestanka malih fragmenata staništa. Najpovoljnija staništa poput suhih travnjaka opstaju uglavnom na termofilnim strmim obroncima brežuljaka i planina, dok su drugdje gotovo u potpunosti nestala. Zahvaljujući tome su i brojnosti vrsta vezana uz takva staništa, poput $P$. thersites ili $P$. daphnis, iznimno male. Isto tako, vlažni travnjaci uglavnom su degradirani ili prekriveni invazivnim biljkama, onemogućujući dugoročni opstanak močvarnih vrsta na području Hrvatskog zagorja. Opstanak rijetkih i ugroženih vrsta leptira na području Hrvatskog zagorja u potpunosti ovisi o usmjerenim manjim i većim akcijama revitalizacije staništa. 


\begin{tabular}{|c|c|c|c|c|c|c|c|c|c|c|c|c|c|c|c|}
\hline صّ & 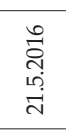 & 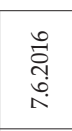 & 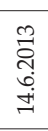 & 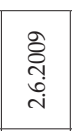 & 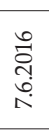 & 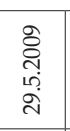 & 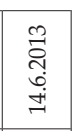 & 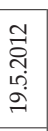 & 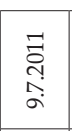 & 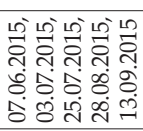 & 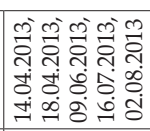 & 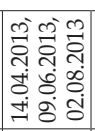 & 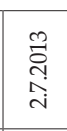 & 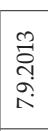 & 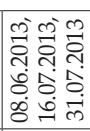 \\
\hline z & 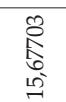 & $\begin{array}{l}\text { 员 } \\
\text { 量 } \\
\text { 昜 }\end{array}$ & 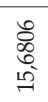 & 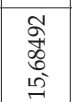 & 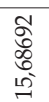 & $\begin{array}{l}\text { के } \\
\text { के } \\
\text { के } \\
\text { ñ }\end{array}$ & $\begin{array}{l}\hat{0} \\
\hat{\alpha} \\
\hat{\sigma} \\
\text { ñ }\end{array}$ & \begin{tabular}{l}
$\overline{2}$ \\
\multicolumn{2}{c}{} \\
s)
\end{tabular} & 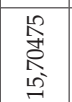 & 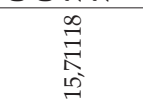 & 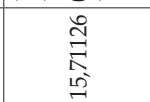 & 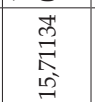 & 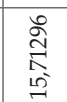 & 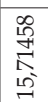 & 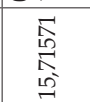 \\
\hline$\omega$ & 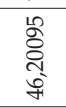 & 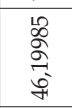 & 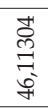 & 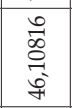 & 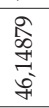 & 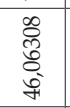 & 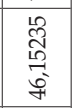 & 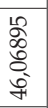 & 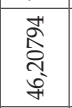 & 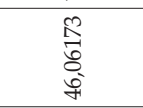 & 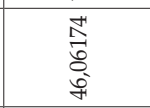 & 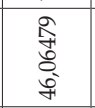 & 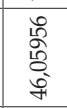 & 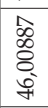 & 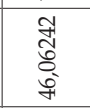 \\
\hline 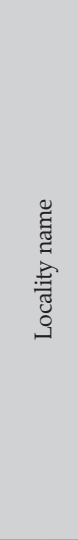 & 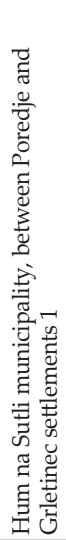 & 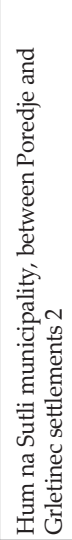 & 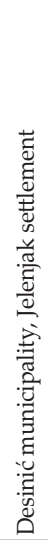 & 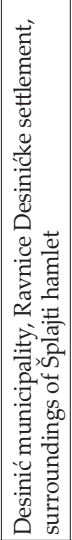 & 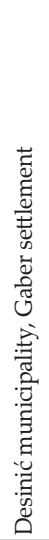 & 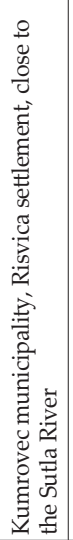 & 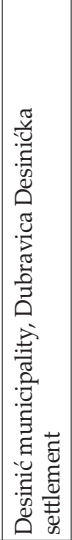 & 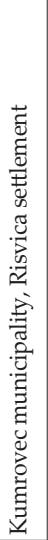 & 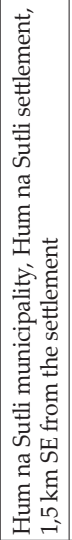 & 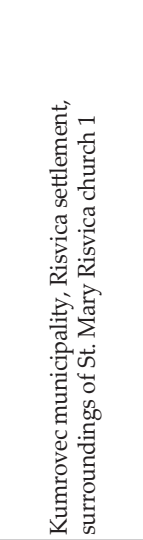 & 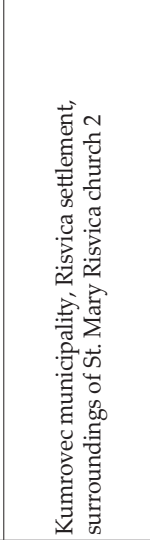 & 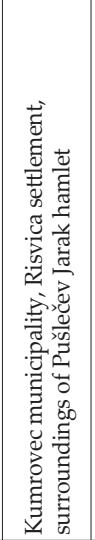 & 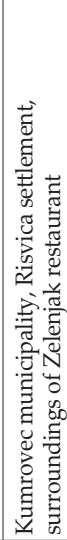 & 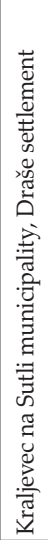 & 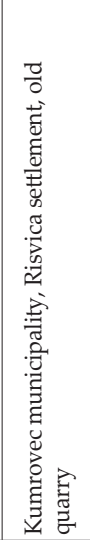 \\
\hline 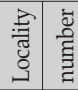 & ने & নి & $\vec{\sim}$ & $\pi$ & $\ddot{\sim}$ & 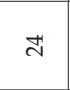 & $\stackrel{2}{\sim}$ & $\stackrel{\sim}{\sim}$ & הે & $\stackrel{\sim}{\sim}$ & ஜे & ले & $\vec{m}$ & లี & 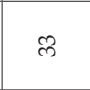 \\
\hline
\end{tabular}

\begin{tabular}{|c|c|c|c|c|c|c|c|c|c|c|c|c|c|c|c|c|c|c|c|}
\hline & ڤँ๊ & 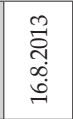 & 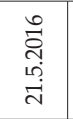 & 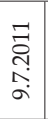 & 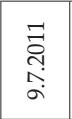 & 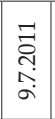 & 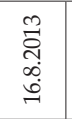 & 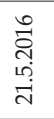 & 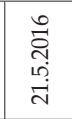 & 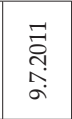 & 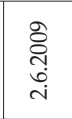 & 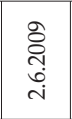 & $\begin{array}{l}\text { ठे̀े } \\
\text { तิ } \\
\text { ָें }\end{array}$ & $\begin{array}{l}\text { సี } \\
\text { స్. } \\
\text { సิ }\end{array}$ & 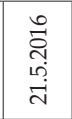 & \begin{tabular}{l}
$m$ \\
\multicolumn{1}{c}{} \\
$\infty$ \\
$\infty$ \\
$\stackrel{0}{0}$
\end{tabular} & 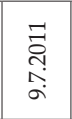 & 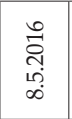 & 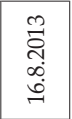 \\
\hline & z & 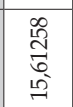 & 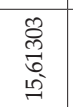 & 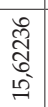 & 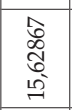 & $\begin{array}{l}\text { जी } \\
\text { త్ర } \\
\stackrel{2}{n}\end{array}$ & 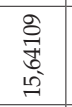 & 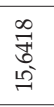 & $\begin{array}{l}\text { 突 } \\
\text { 点 }\end{array}$ & 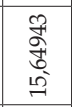 & $\begin{array}{l}\sqrt[3]{0} \\
\stackrel{2}{n}\end{array}$ & 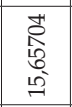 & 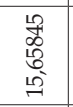 & 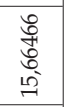 & 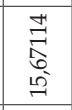 & 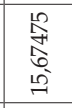 & 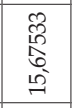 & $\begin{array}{l}8 \\
8 \\
0 \\
6 \\
10 \\
10\end{array}$ & 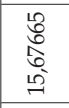 \\
\hline & 10 & 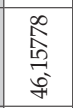 & 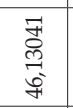 & 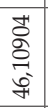 & 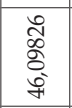 & 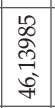 & 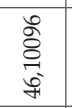 & 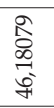 & 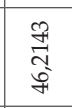 & 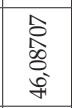 & 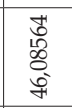 & 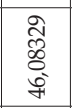 & 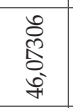 & 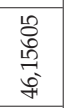 & 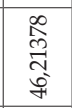 & 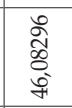 & 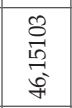 & 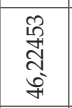 & $\begin{array}{l}\text { Iี } \\
\text { ন্ } \\
\text { ț }\end{array}$ \\
\hline & 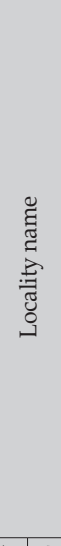 & 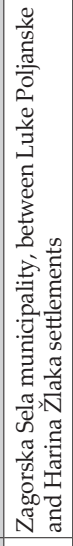 & 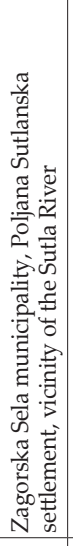 & 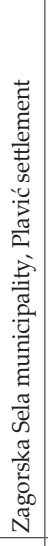 & 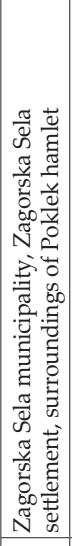 & 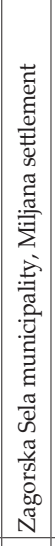 & 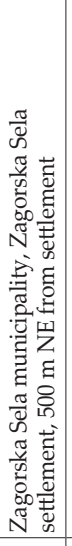 & 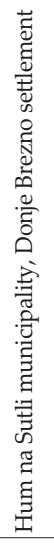 & 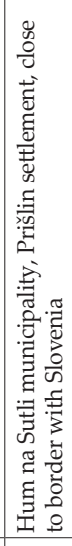 & 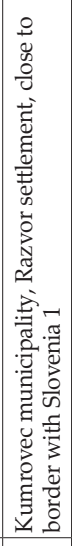 & 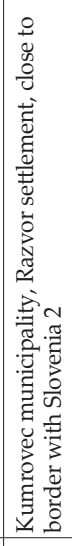 & 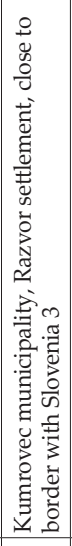 & 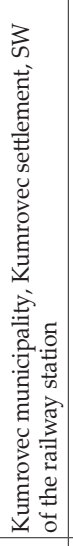 & 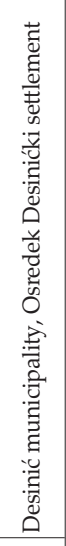 & 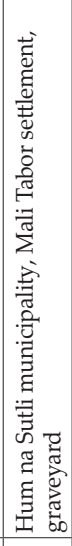 & 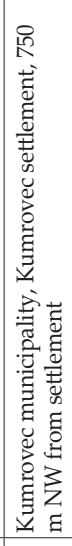 & 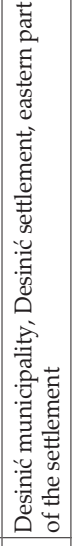 & 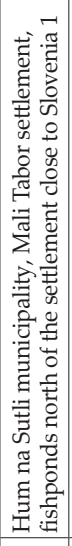 & 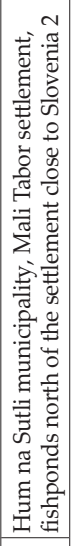 \\
\hline & 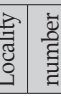 & $r$ & $N$ & $\infty$ & $r$ & in & 0 & $\ltimes$ & $\infty$ & $a$ & ㅇ & $\exists$ & $\approx$ & $\stackrel{2}{\sim}$ & 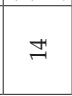 & $\stackrel{2}{\sim}$ & $\stackrel{?}{2}$ & $\therefore$ & $\stackrel{\infty}{\sim}$ \\
\hline
\end{tabular}




\begin{tabular}{|c|c|c|c|c|c|c|c|c|c|c|c|c|c|c|c|c|c|c|}
\hline 䒕 & 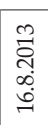 & 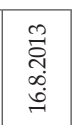 & 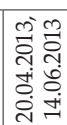 & 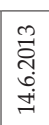 & 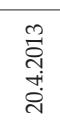 & 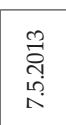 & 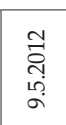 & 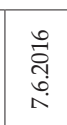 & 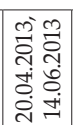 & 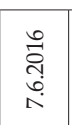 & 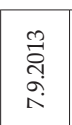 & 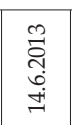 & 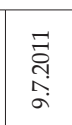 & 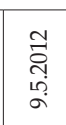 & 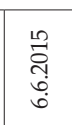 & 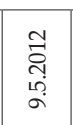 & 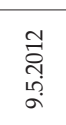 & $\begin{array}{l}\text { ठे } \\
\text { ते } \\
\text { ते }\end{array}$ \\
\hline z & 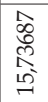 & $\begin{array}{l}\bar{\sigma} \\
\text { న } \\
\text { م) }\end{array}$ & 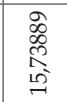 & 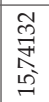 & 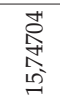 & 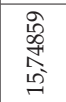 & 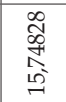 & 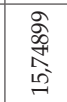 & $\begin{array}{l}\text { त̂ } \\
\text { مू } \\
\text { مी }\end{array}$ & $\begin{array}{l}\stackrel{2}{2} \\
\stackrel{2}{\wedge} \\
10 \\
\end{array}$ & 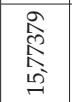 & 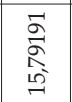 & $\begin{array}{l}\infty \\
\tilde{\delta} \\
\infty \\
\infty \\
\text { Ln }\end{array}$ & $\begin{array}{l}10 \\
80 \\
8 \\
10 \\
10\end{array}$ & 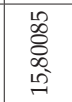 & 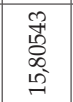 & 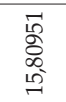 & 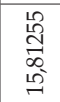 \\
\hline tr & 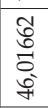 & 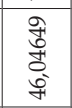 & 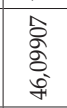 & 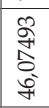 & 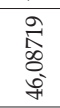 & 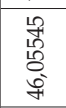 & 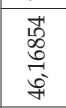 & 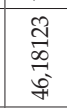 & $\begin{array}{l}\approx 0 \\
0 \\
0 \\
5 \\
5\end{array}$ & 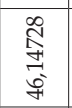 & $\begin{array}{l}\text { 亲 } \\
\text { 号 } \\
\text { ti }\end{array}$ & 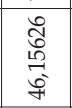 & 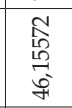 & 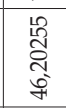 & 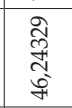 & 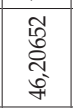 & $\begin{array}{l}\text { 고 } \\
\text { స్ } \\
\text { ț }\end{array}$ & $\begin{array}{l}\overrightarrow{8} \\
\text { o. } \\
\text { fi }\end{array}$ \\
\hline 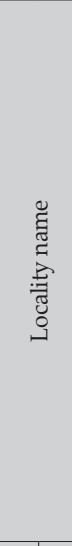 & 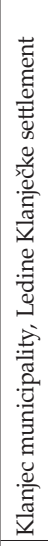 & 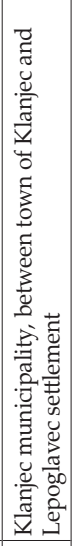 & 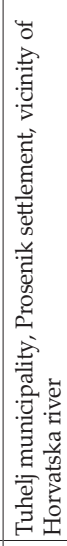 & 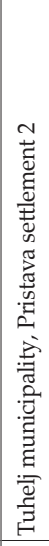 & 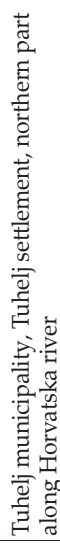 & 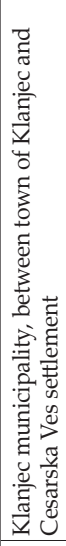 & 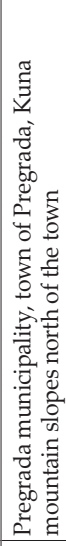 & 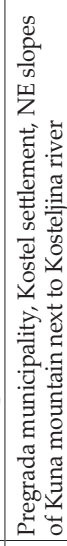 & 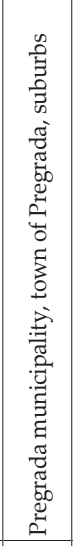 & 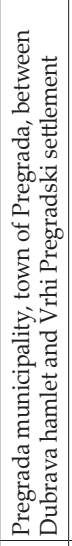 & 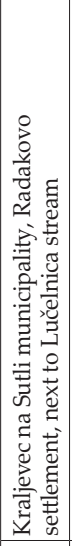 & 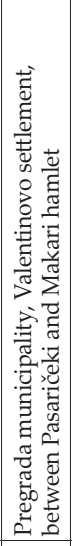 & 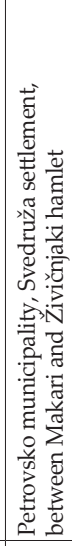 & 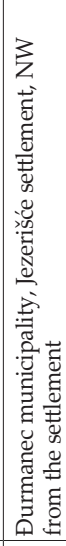 & 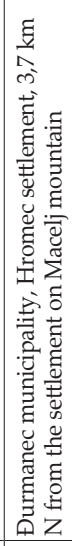 & 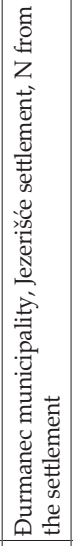 & 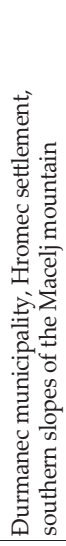 & 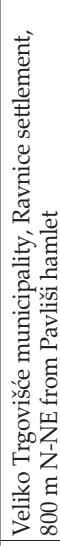 \\
\hline 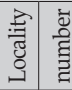 & in & है & กิ & ถి & H & in & in & in & in & in & 8 & 5 & $\delta$ & 3 & ठ十 & 18 & 8 & 6 \\
\hline
\end{tabular}

\begin{tabular}{|c|c|c|c|c|c|c|c|c|c|c|c|c|c|c|c|c|}
\hline$\frac{\pi}{\pi}$ & 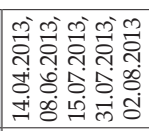 & 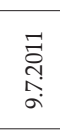 & 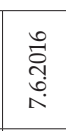 & 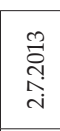 & 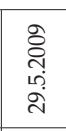 & 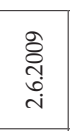 & 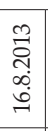 & 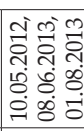 & $\begin{array}{l}\vec{\nabla} \\
\text { م̆ }\end{array}$ & 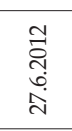 & 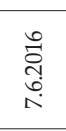 & $\begin{array}{l}0 \\
0 \\
0 \\
0 \\
0 \\
0 \\
0 \\
0 \\
0 \\
0 \\
0\end{array}$ & 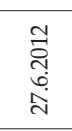 & 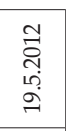 & $\begin{array}{l}\vec{\Xi} \\
\text { ָุ } \\
\text { مू }\end{array}$ & 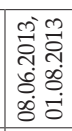 \\
\hline z & 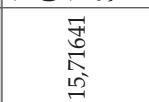 & 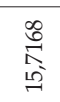 & 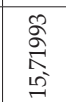 & 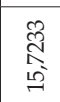 & $\begin{array}{l}\infty \\
\infty \\
\widetilde{N} \\
\hat{N} \\
n\end{array}$ & 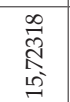 & 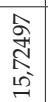 & 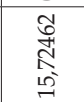 & 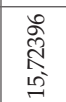 & 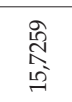 & 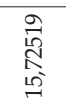 & 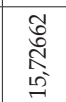 & 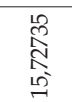 & 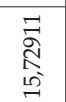 & 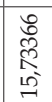 & 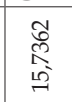 \\
\hline w & 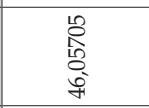 & 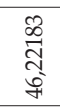 & $\begin{array}{l}\infty \\
\frac{\infty}{6} \\
\frac{1}{0}\end{array}$ & $\begin{array}{l}\overrightarrow{0} \\
\text { o } \\
\text { के }\end{array}$ & 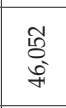 & $\begin{array}{l}\text { 突 } \\
\text { के } \\
\text { के }\end{array}$ & 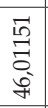 & $\begin{array}{l}\infty \\
0 \\
\infty \\
0 \\
0 \\
0+\end{array}$ & 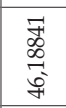 & 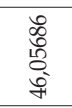 & 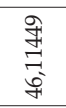 & 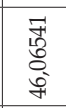 & 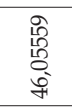 & $\begin{array}{l}\text { aे } \\
\text { ปे } \\
\text { की }\end{array}$ & 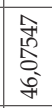 & 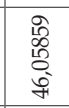 \\
\hline 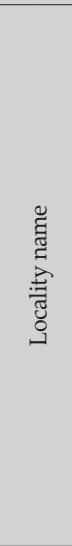 & 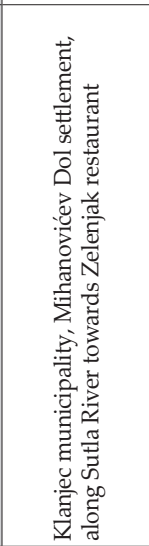 & 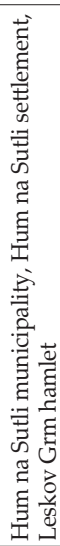 & 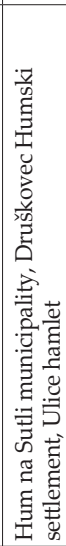 & 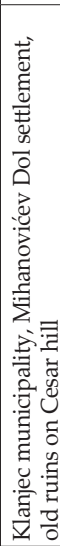 & 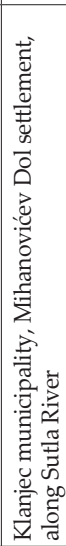 & 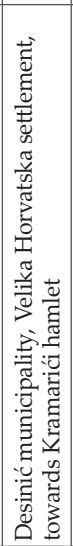 & 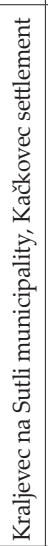 & 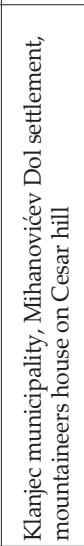 & 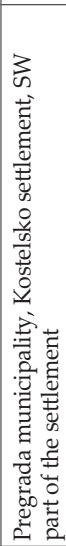 & 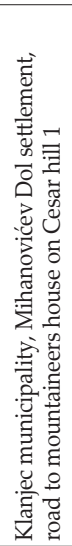 & 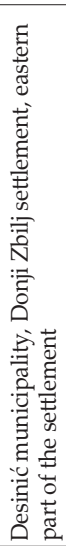 & 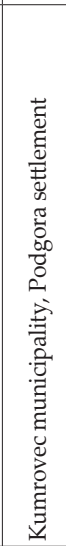 & 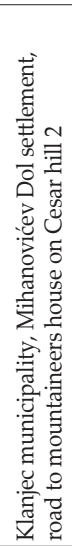 & 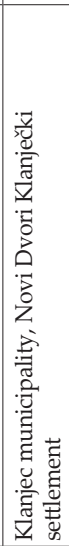 & 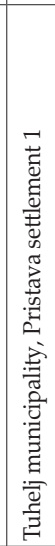 &  \\
\hline 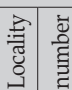 & ल゙ & $\stackrel{L}{m}$ & ల & लि & $\stackrel{\infty}{\infty}$ & के & o & $F$ & I & F & J & L & $\mathscr{f}$ & f & $\stackrel{\infty}{q}$ & भे \\
\hline
\end{tabular}




\begin{tabular}{|c|c|c|c|c|c|c|c|c|c|c|c|c|c|c|c|c|}
\hline$\frac{8}{\pi}$ & 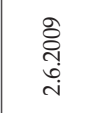 & 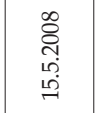 & 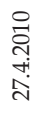 & 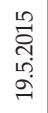 & 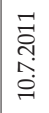 & 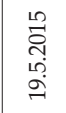 & 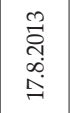 & $\begin{array}{l}\text { ते } \\
\text { तై } \\
\text { तें }\end{array}$ & 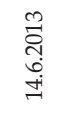 & $\begin{array}{l}\text { בิ } \\
\text { तิ } \\
\text { เุ. }\end{array}$ & $\begin{array}{l}\text { तิ } \\
\text { तై } \\
\text { ते }\end{array}$ & 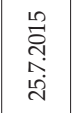 & 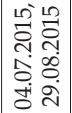 & 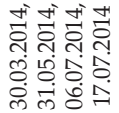 & 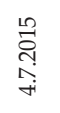 & $\begin{array}{l}\text { ज̃ } \\
\text { तై } \\
\text { ते }\end{array}$ \\
\hline z & $\begin{array}{l}\text { \& } \\
\text { \& } \\
\infty \\
10 \\
12\end{array}$ & 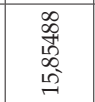 & 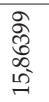 & 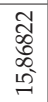 & $\begin{array}{l}\infty \\
\infty \\
\infty \\
\infty \\
12 \\
\end{array}$ & 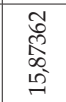 & 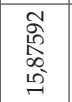 & $\begin{array}{l}8 \\
8 \\
\infty \\
\infty \\
10 \\
10\end{array}$ & 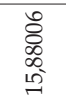 & $\begin{array}{l}\overline{5} \\
\infty \\
\infty \\
10 \\
10\end{array}$ & $\begin{array}{l}\text { Fै } \\
\infty \\
\infty \\
\text { ñ } \\
\end{array}$ & $\begin{array}{l}\overrightarrow{7} \\
\infty \\
\infty \\
\text { in } \\
\end{array}$ & $\begin{array}{l}\infty \\
\hat{\alpha} \\
\infty \\
\infty \\
12\end{array}$ & 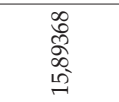 & 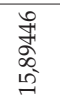 & $\begin{array}{l}\text { ते } \\
\infty \\
\infty \\
\text { हो }\end{array}$ \\
\hline 1 & 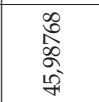 & 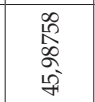 & 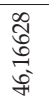 & $\frac{\infty}{\frac{\infty}{\sigma}}$ & 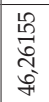 & 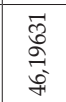 & 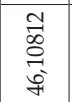 & 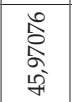 & 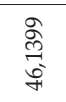 & 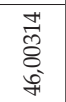 & 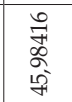 & 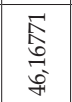 & 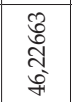 & 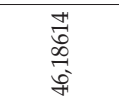 & 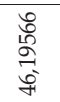 & $\begin{array}{l}\text { के } \\
\text { Ŝ̀ } \\
\text { Lे }\end{array}$ \\
\hline 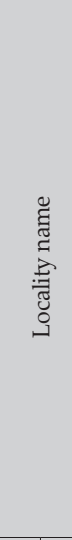 & 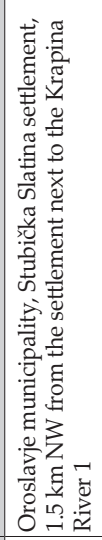 & 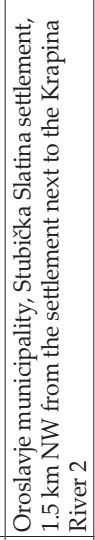 & 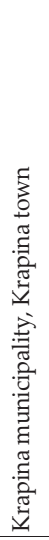 & 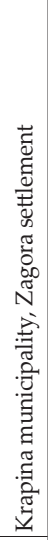 & 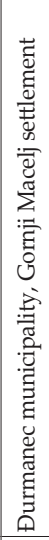 & 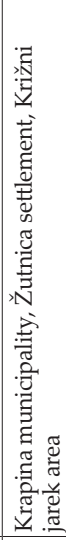 & 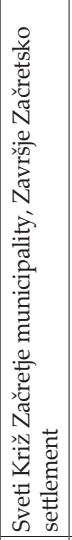 & 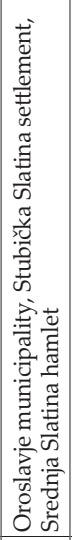 & 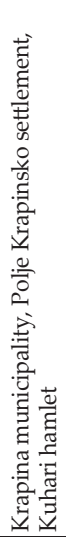 & 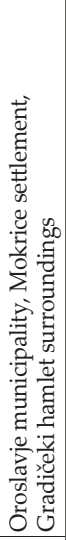 & 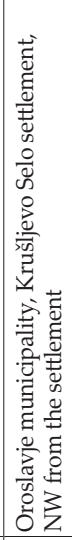 & 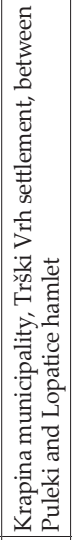 & 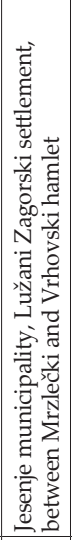 & 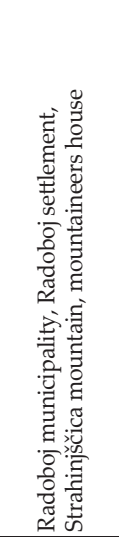 & 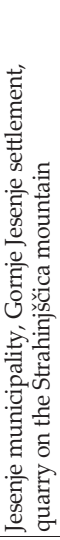 & 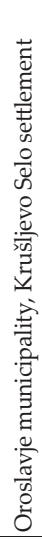 \\
\hline 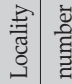 & 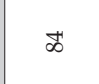 & $\bowtie$ & $\infty$ & $\infty$ & $\infty$ & $\infty$ & 8 & $\sigma$ & $\alpha$ & 2 & \#゙ & ूㅏ & 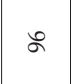 & s & $\stackrel{\infty}{\circ}$ & - \\
\hline
\end{tabular}

\begin{tabular}{|c|c|c|c|c|c|c|c|c|c|c|c|c|c|c|c|c|}
\hline صّ & 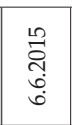 & 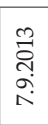 & 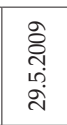 & 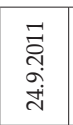 & $\begin{array}{l}\text { तै } \\
\text { तु } \\
\text { ठें }\end{array}$ & 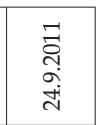 & 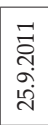 & 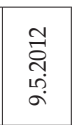 & 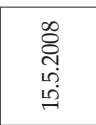 & 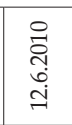 & 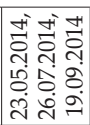 & 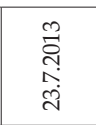 & 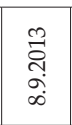 & 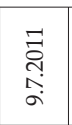 & 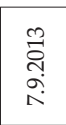 & 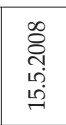 \\
\hline z & 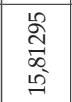 & 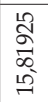 & 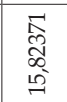 & 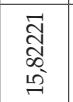 & 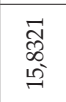 & $\begin{array}{l}\infty \\
\infty \\
\infty \\
\infty \\
10\end{array}$ & 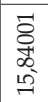 & \begin{tabular}{l}
3 \\
\multirow{5}{*}{} \\
12 \\
12
\end{tabular} & 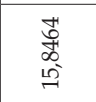 & 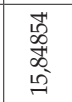 & 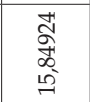 & 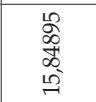 & 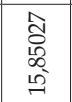 & $\begin{array}{l}\text { oे } \\
\infty \\
\infty \\
\text { ñ }\end{array}$ & $\begin{array}{l}\infty \\
\text { ồ } \\
\infty \\
12 \\
12\end{array}$ & 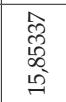 \\
\hline$\omega$ & 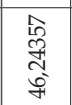 & 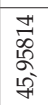 & 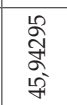 & 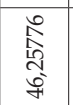 & 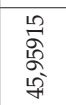 & $\begin{array}{l}\text { N } \\
\text { तू } \\
\text { L }\end{array}$ & 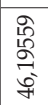 & $\begin{array}{l}\text { ț } \\
\text { ते } \\
\text { तू }\end{array}$ & 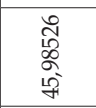 & $\begin{array}{l}\text { sे } \\
\text { के } \\
\text { گे }\end{array}$ & 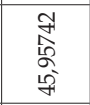 & 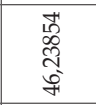 & 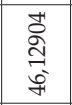 & $\begin{array}{l}\qquad 8 \\
0 \\
0 \\
6 \\
5 \\
5\end{array}$ & 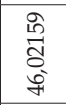 & $\begin{array}{l}\frac{m}{\infty} \\
0 \\
\alpha \\
\text { ò }\end{array}$ \\
\hline 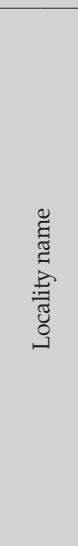 & 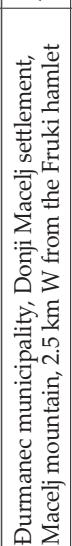 & 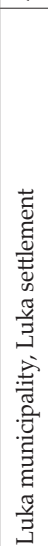 & 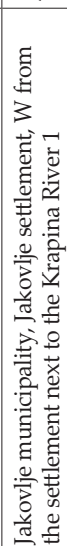 & 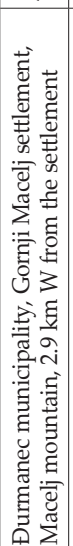 & 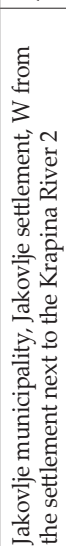 & 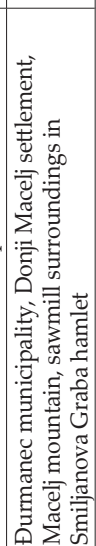 & 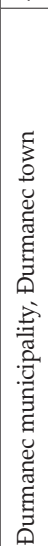 & 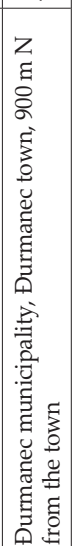 & 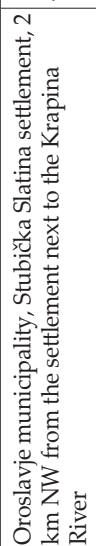 & 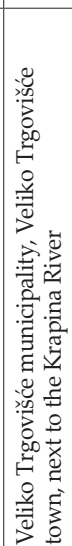 & 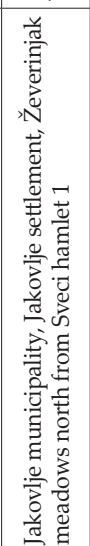 & 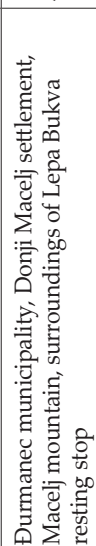 & 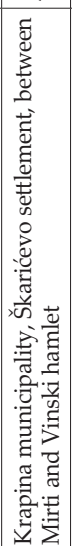 & 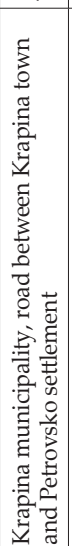 & 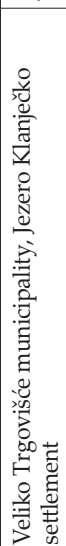 & 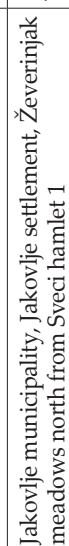 \\
\hline 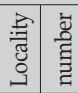 & $\infty$ & 6) & $R$ & $\Sigma$ & $\mathbb{N}$ & 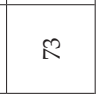 & स & $\mathfrak{R}$ & $\stackrel{2}{\curvearrowleft}$ & 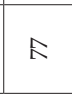 & $\stackrel{\infty}{\wedge}$ & ฉ & $\infty$ & $\vec{\infty}$ & $\infty$ & 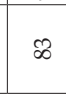 \\
\hline
\end{tabular}




\begin{tabular}{|c|c|c|c|c|c|c|c|c|c|c|c|c|c|c|c|}
\hline صّ & 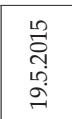 & $\begin{array}{l}0 \\
\text { సิ } \\
\text { ถุ } \\
\infty\end{array}$ & 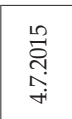 & 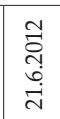 & 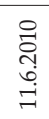 & 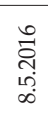 & 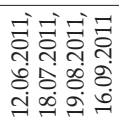 & 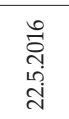 & 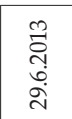 & 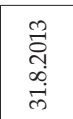 & 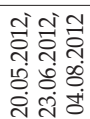 & 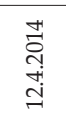 & 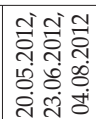 & 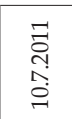 & 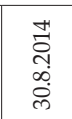 \\
\hline$z$ & 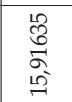 & 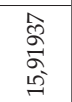 & $\begin{array}{l}\infty \\
\infty \\
\infty \\
\sigma \\
\tilde{n}^{2}\end{array}$ & $\begin{array}{l}\text { बे } \\
\text { बे } \\
\text { Iે }\end{array}$ & 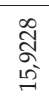 & 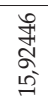 & 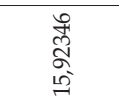 & 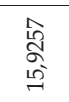 & 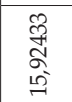 & 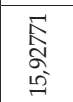 & $\begin{array}{l}\bar{్} \\
\text { న్ } \\
\text { దે }\end{array}$ & $\begin{array}{l}\text { สิ } \\
\text { ๙ิ } \\
\text { เి }\end{array}$ & $\begin{array}{l}\infty \\
10 \\
\kappa \\
\text { L్ }\end{array}$ & 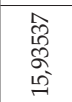 & 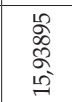 \\
\hline 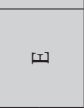 & 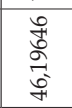 & $\begin{array}{l}\frac{1}{2} \\
8 \\
5 \\
5 \\
5\end{array}$ & 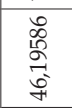 & 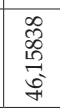 & 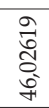 & 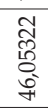 & $\begin{array}{l}\stackrel{0}{\infty} \\
\stackrel{5}{5}\end{array}$ & 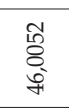 & 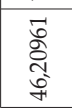 & 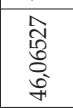 & \begin{tabular}{l}
$\infty$ \\
0 \\
$o$ \\
0 \\
\multirow{6}{0}{}
\end{tabular} & 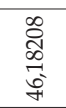 & 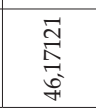 & 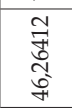 & 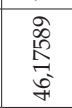 \\
\hline 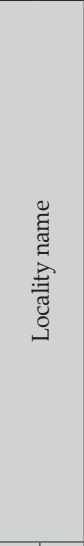 & 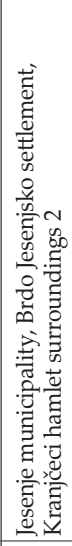 & 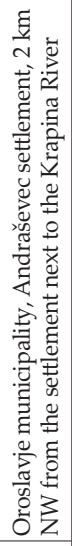 & 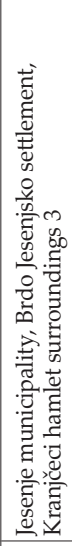 & 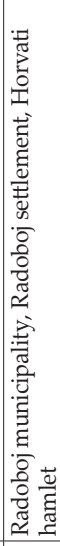 & 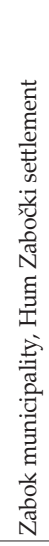 & 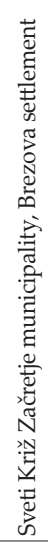 & 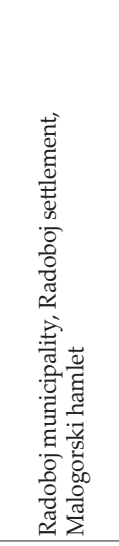 & 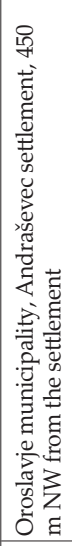 & 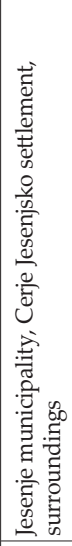 & 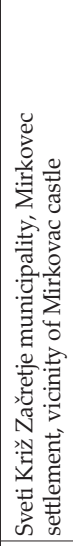 & 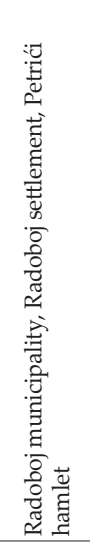 & 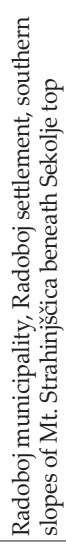 & 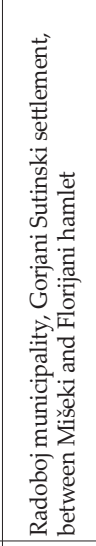 & 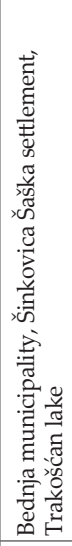 & 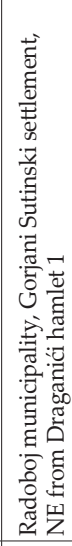 \\
\hline 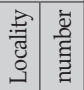 & $\underset{\exists}{ت}$ & 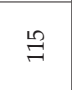 & $\stackrel{?}{=}$ & $\hat{\exists}$ & $\stackrel{\infty}{=}$ & $\stackrel{\partial}{7}$ & త్రి & $\bar{\Xi}$ & ปี & $\tilde{\Xi}$ & $\mathbb{J}$ & $\stackrel{\stackrel{2}{\beth}}{ }$ & $\stackrel{\mathbb{I}}{ }$ & సิ & $\stackrel{\mathbb{N}}{\mathbb{N}}$ \\
\hline
\end{tabular}

\begin{tabular}{|c|c|c|c|c|c|c|c|c|c|c|c|c|c|c|}
\hline ฮँ & 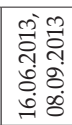 & 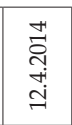 & $\begin{array}{l}\text { 号 } \\
\text { ते } \\
\text { ते }\end{array}$ & 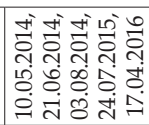 & 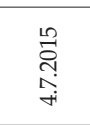 & 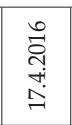 & 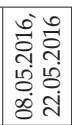 & 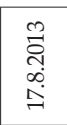 & 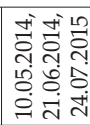 & 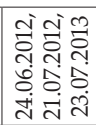 & 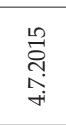 & 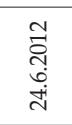 & $\begin{array}{l}\text { ב్̃ } \\
\text { तु } \\
\text { ते }\end{array}$ & 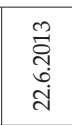 \\
\hline$z$ & 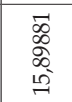 & 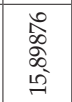 & 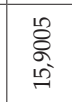 & 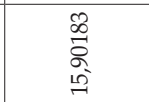 & 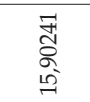 & 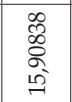 & 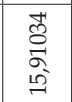 & 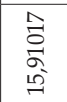 & $\begin{array}{l}\text { के } \\
\text { कू } \\
\text { 2ूे }\end{array}$ & 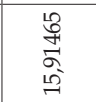 & 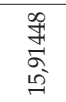 & 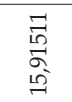 & 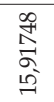 & 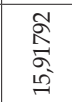 \\
\hline 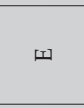 & 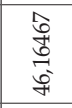 & 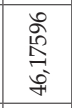 & 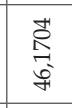 & $\frac{\hat{A}}{\frac{5}{6}}$ & 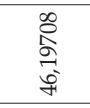 & 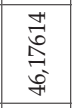 & 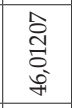 & $\begin{array}{l}\text { के } \\
5 \\
5 \\
\text { ț }\end{array}$ & 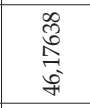 & 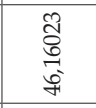 & 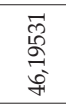 & 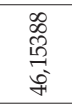 & 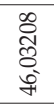 & $\begin{array}{l}\infty \\
\vdots \\
5 \\
0 \\
0\end{array}$ \\
\hline 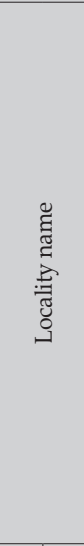 & 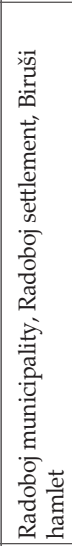 & 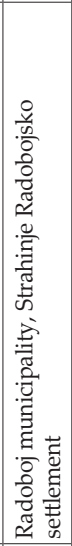 & 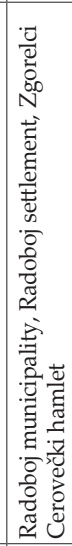 & 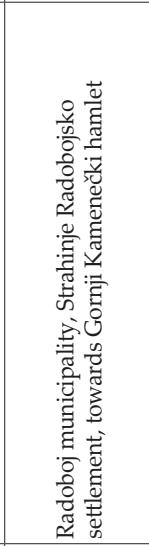 & 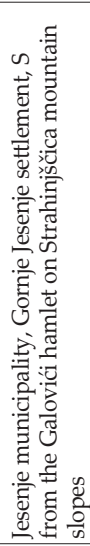 & 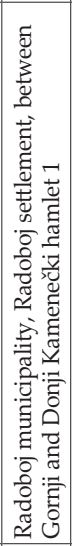 & 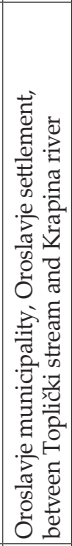 & 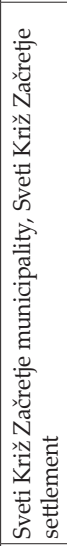 & 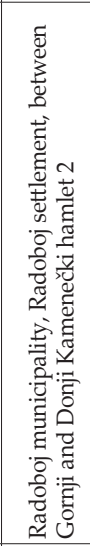 & 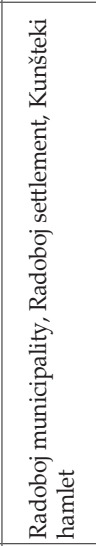 & 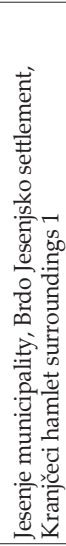 & 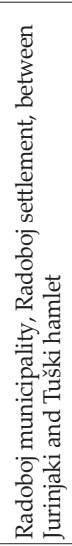 & 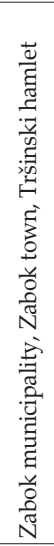 & 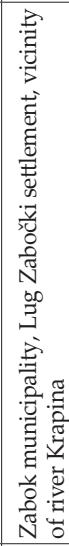 \\
\hline 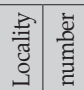 & $\stackrel{ }{~}$ & 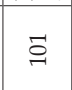 & 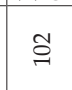 & $\stackrel{\overbrace{}}{\varrho}$ & $\stackrel{t}{\circ}$ & $\stackrel{\stackrel{ }{O}}{\sim}$ & $\stackrel{\sim}{\circ}$ & $\stackrel{\circ}{\rho}$ & 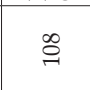 & 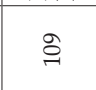 & $\stackrel{ }{\exists}$ & $\exists$ & 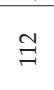 & $\stackrel{m}{=}$ \\
\hline
\end{tabular}




\begin{tabular}{|c|c|c|c|c|c|c|c|c|c|c|c|c|c|c|c|c|}
\hline$\frac{8}{\pi}$ & 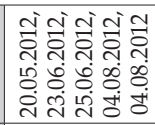 & 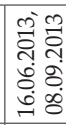 & 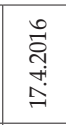 & 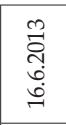 & 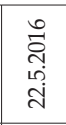 & 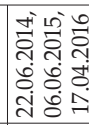 & 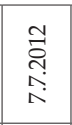 & 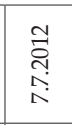 & 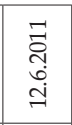 & 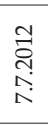 & 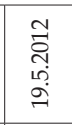 & 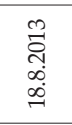 & 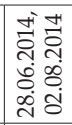 & 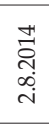 & 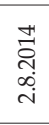 & $\begin{array}{l}\text { तี } \\
\text { तై } \\
\text { तें }\end{array}$ \\
\hline z & 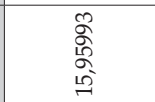 & 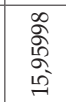 & 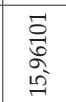 & 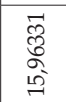 & 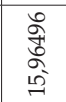 & 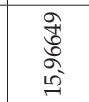 & 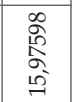 & $\begin{array}{l}\infty \\
10 \\
0 \\
\alpha \\
10 \\
12\end{array}$ & 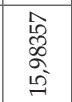 & $\begin{array}{l}2 \\
10 \\
0 \\
2 \\
10 \\
12\end{array}$ & 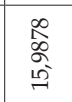 & 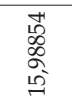 & 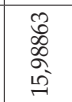 & 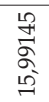 & 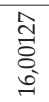 & $\begin{array}{l}0 \\
0 \\
o \\
o \\
0\end{array}$ \\
\hline 1 & 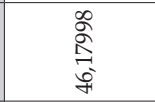 & 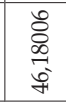 & 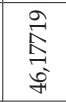 & 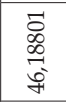 & 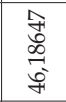 & 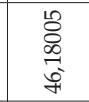 & $\begin{array}{l}0 \\
\frac{0}{5} \\
\text { st }\end{array}$ & 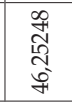 & 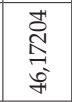 & 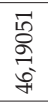 & 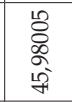 & 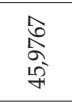 & 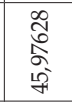 & 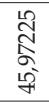 & 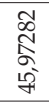 & 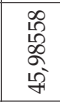 \\
\hline 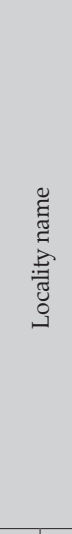 & 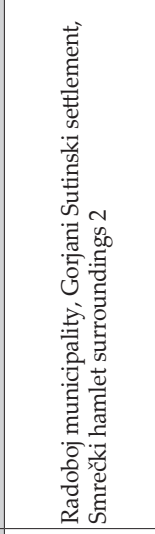 & 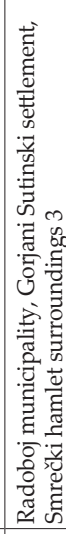 & 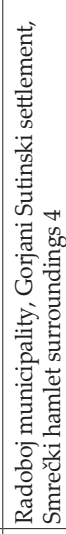 & 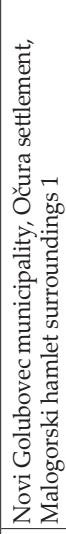 & 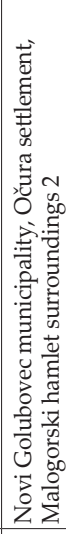 & 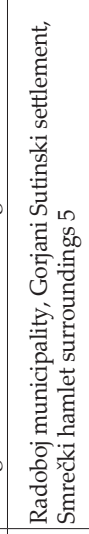 & 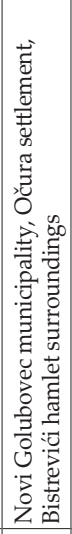 & 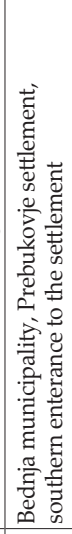 & 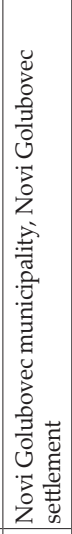 & 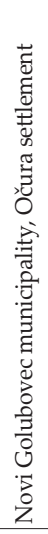 & 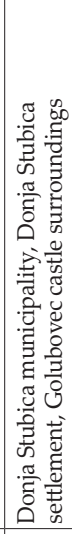 & 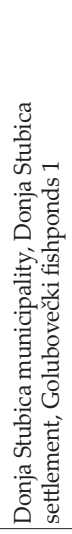 & 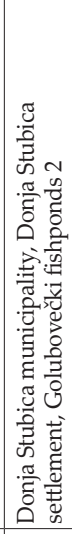 & 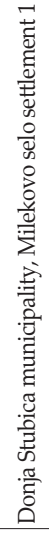 & 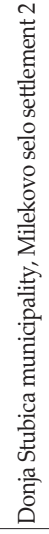 & 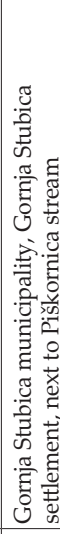 \\
\hline 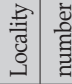 & $\stackrel{9}{\exists}$ & $\mathbb{J}$ & 孚 & $\stackrel{\text { I }}{=}$ & f & $\stackrel{\infty}{\mathbb{I}}$ & Iे & ஜ̊ & $\overrightarrow{\text { Dn }}$ & กิ & مొ & 营 & 啬 & 윰 & 会 & $\stackrel{\infty}{\stackrel{\infty}{2}}$ \\
\hline
\end{tabular}

\begin{tabular}{|c|c|c|c|c|c|c|c|c|c|c|c|c|c|c|}
\hline$\frac{\mathscr{z}}{\tilde{\varpi}}$ & 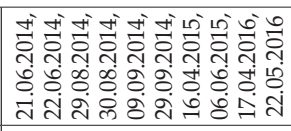 & $\begin{array}{l}m \\
\stackrel{2}{5} \\
\infty \\
\infty \\
\dot{\infty}\end{array}$ & $\begin{array}{l}\text { तै } \\
\text { त़े } \\
\text { ते }\end{array}$ & 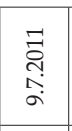 & $\begin{array}{l}m \\
\stackrel{m}{1} \\
\infty \\
\infty \\
\infty \\
\infty\end{array}$ & 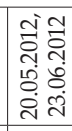 & 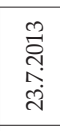 & 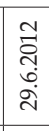 & 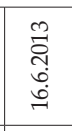 & $\begin{array}{l}\overrightarrow{\widetilde{T}} \\
\stackrel{+}{\alpha} \\
\text { مू }\end{array}$ & 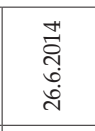 & 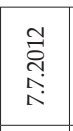 & 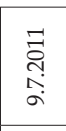 & 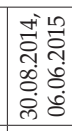 \\
\hline$z$ & $\begin{array}{l}\text { สี } \\
\text { నू } \\
\text { ஸे }\end{array}$ & 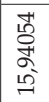 & 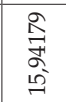 & $\begin{array}{l}\text { สี } \\
\text { सิ } \\
\text { ลี }\end{array}$ & $\begin{array}{l}\text { สี } \\
\text { \&ิ } \\
\text { Iñ }\end{array}$ & 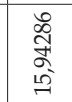 & 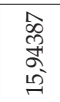 & 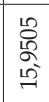 & 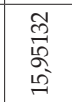 & $\begin{array}{l}\text { भे } \\
\text { ूू } \\
\text { ñ }\end{array}$ & 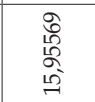 & 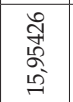 & 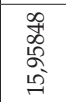 & $\begin{array}{l}\text { న్ } \\
0 \\
\alpha \\
12\end{array}$ \\
\hline س & 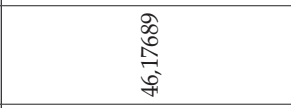 & 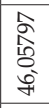 & 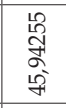 & 高 & 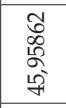 & 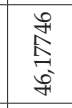 & 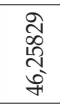 & 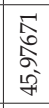 & 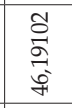 & $\begin{array}{l}\frac{1}{2} \\
\frac{2}{2} \\
\frac{1}{2}\end{array}$ & $\begin{array}{l}\overrightarrow{\widetilde{N}} \\
\text { ๙ूे } \\
\text { ईे }\end{array}$ & 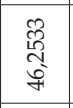 & 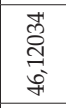 & 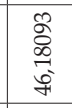 \\
\hline 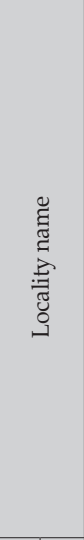 & 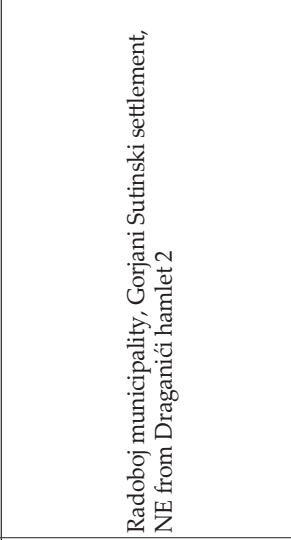 & 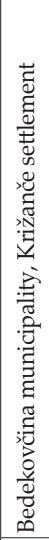 & 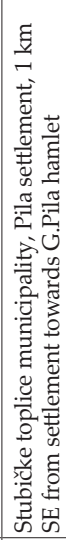 & 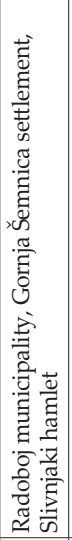 & 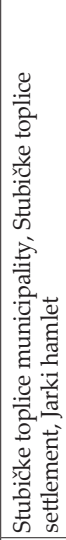 & 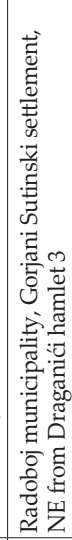 & 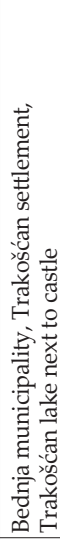 & 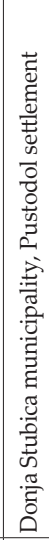 & 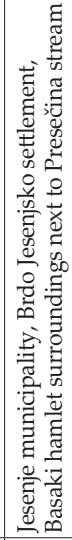 & 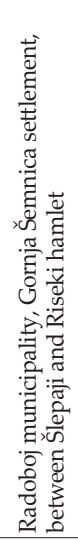 & 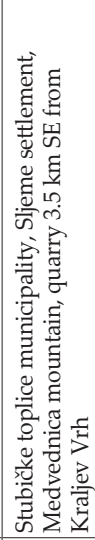 & 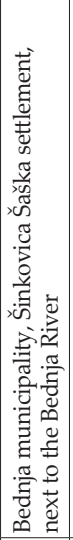 & 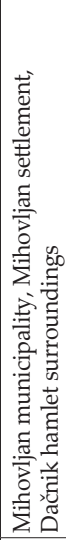 & 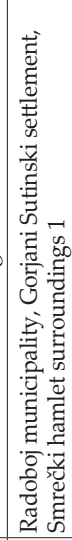 \\
\hline 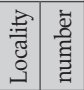 & సે & త్తి & $\vec{m}$ & 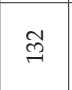 & $\stackrel{m}{a}$ & $\stackrel{\vec{d}}{\sim}$ & 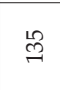 & 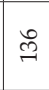 & $\stackrel{\widehat{M}}{\Omega}$ & $\stackrel{\infty}{\stackrel{\infty}{c}}$ & ले & 악 & $\exists$ & $\exists$ \\
\hline
\end{tabular}




\begin{tabular}{|c|c|c|c|c|c|c|c|c|c|c|c|c|c|c|}
\hline صّ & $\begin{array}{l}\overline{\vec{s}} \\
\stackrel{N}{人}\end{array}$ & 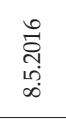 & $\begin{array}{l}\text { तี } \\
\text { तై } \\
\text { वें }\end{array}$ & $\begin{array}{l}\text { ㄱ. } \\
\stackrel{N}{人}\end{array}$ & 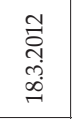 & 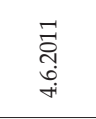 & 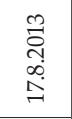 & 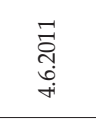 & 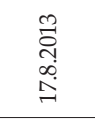 & 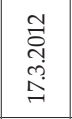 & 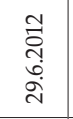 & 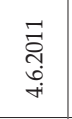 & 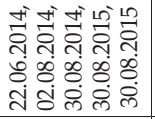 & 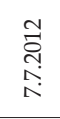 \\
\hline z & $\begin{array}{l}\text { कo } \\
\text { ô } \\
0 \\
\text { c. }\end{array}$ & 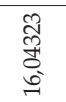 & $\begin{array}{l}\qquad 8 \\
8 \\
0 \\
0 \\
0 \\
0\end{array}$ & 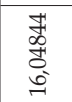 & $\begin{array}{l}\infty \\
\infty \\
0 \\
0 \\
0 \\
0 \\
0\end{array}$ & $\begin{array}{l}\text { J } \\
\text { 足 } \\
0 \\
0 \\
0\end{array}$ & 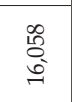 & 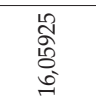 & \begin{tabular}{l}
0 \\
\multirow{0}{0}{} \\
0 \\
0
\end{tabular} & $\begin{array}{l}\text { for } \\
\text { o } \\
0 \\
0\end{array}$ & 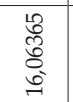 & 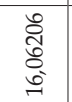 & $\begin{array}{l}0 \\
\infty \\
\text { ర్ } \\
0 \\
\sigma\end{array}$ & 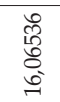 \\
\hline 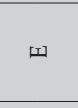 & 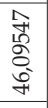 & 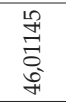 & 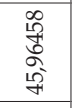 & 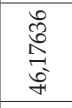 & 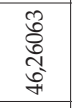 & 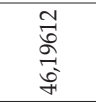 & 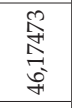 & 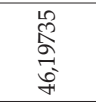 & 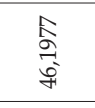 & $\begin{array}{l}\text { त̃ } \\
\text { त̂̃ } \\
\text { L̆ }\end{array}$ & 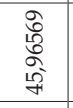 & 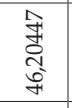 & 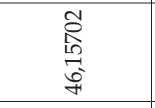 & 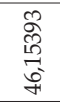 \\
\hline 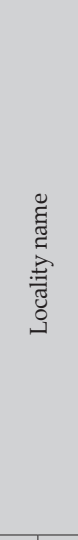 & 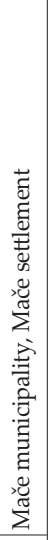 & 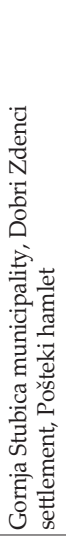 & 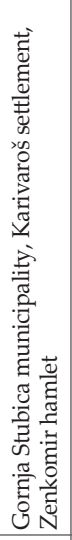 & 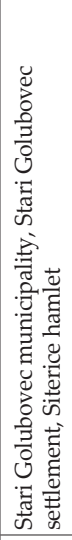 & 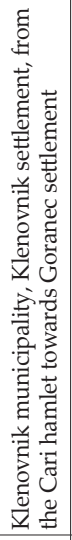 & 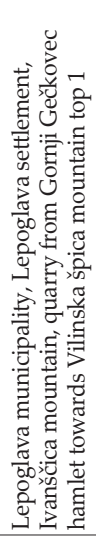 & 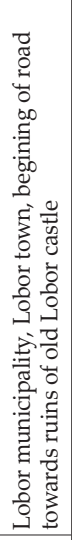 & 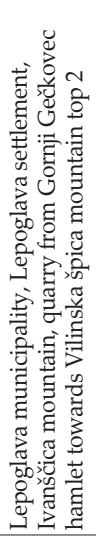 & 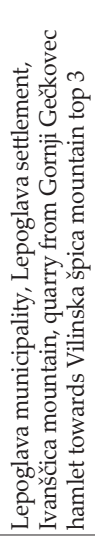 & 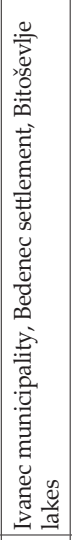 & 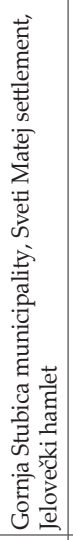 & 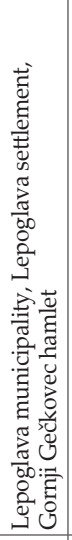 & 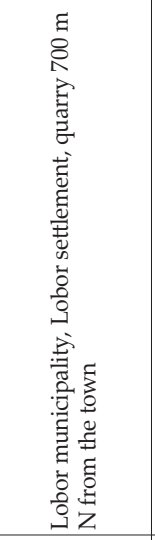 & 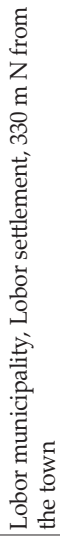 \\
\hline 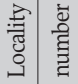 & $\stackrel{2}{2}$ & $\triangleq$ & $\stackrel{\infty}{\subseteq}$ & $\stackrel{શ}{\widehat{\imath}}$ & $\stackrel{\infty}{\sim}$ & $\underset{\sim}{\sigma}$ & $\stackrel{\widetilde{\infty}}{\sim}$ & $\stackrel{\mathscr{O}}{\sim}$ & $\underset{\sim}{\stackrel{D}{\circ}}$ & $\stackrel{\mathbb{\infty}}{\sim}$ & $\stackrel{\infty}{\sim}$ & $\stackrel{\infty}{\sim}$ & $\stackrel{\infty}{\stackrel{\infty}{\sim}}$ & $\stackrel{\triangleright}{\infty}$ \\
\hline
\end{tabular}

\begin{tabular}{|c|c|c|c|c|c|c|c|c|c|c|c|c|c|c|c|c|c|}
\hline صّ & \begin{tabular}{l}
$m$ \\
\multicolumn{1}{|c}{} \\
$\infty$ \\
$\infty$ \\
$\infty$ \\
$\sim$
\end{tabular} & 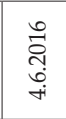 & 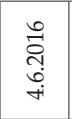 & 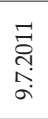 & 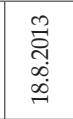 & 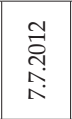 & 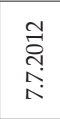 & $\begin{array}{l}\text { त्र } \\
\text { तె } \\
\text { ते }\end{array}$ & 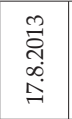 & 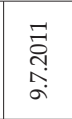 & 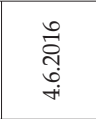 & 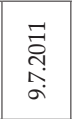 & 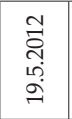 & $\begin{array}{l}\text { तี } \\
\text { ते } \\
\text { त्र } \\
\text { ते }\end{array}$ & 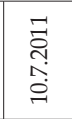 & 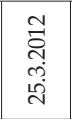 & 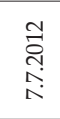 \\
\hline$z$ & 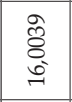 & 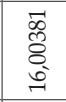 & 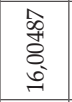 & 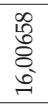 & $\begin{array}{l}8 \\
0 \\
0 \\
5 \\
0 \\
0\end{array}$ & 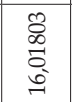 & 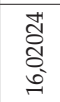 & 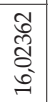 & $\begin{array}{l}\infty \\
\widetilde{\pi} \\
\text { ડ̦ } \\
\text { s. }\end{array}$ & \begin{tabular}{l}
0 \\
\multirow{1}{d}{} \\
s.
\end{tabular} & 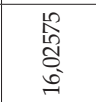 & $\begin{array}{l}\text { तू } \\
\text { ડे } \\
\text { ڤ్ }\end{array}$ & $\begin{array}{l}\text { ते } \\
\text { o } \\
\text { o } \\
\text { s. }\end{array}$ & 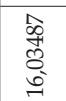 & 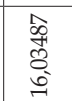 & $\begin{array}{l}\hat{0} \\
\delta \\
\delta \\
0 \\
0\end{array}$ & 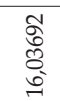 \\
\hline$\omega$ & 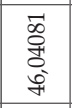 & 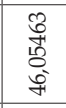 & 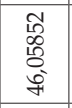 & $\begin{array}{l}\infty \\
\stackrel{0}{7} \\
\stackrel{7}{5}\end{array}$ & 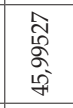 & 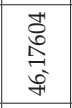 & 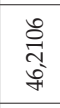 & 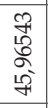 & 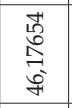 & 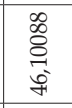 & $\begin{array}{l}\text { के } \\
\text { ఫे } \\
\text { s. }\end{array}$ & 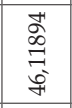 & $\begin{array}{l}\vec{F} \\
\text { ડू } \\
\text { \&े }\end{array}$ & 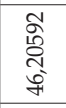 & 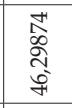 & 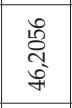 & 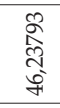 \\
\hline 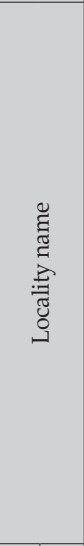 & 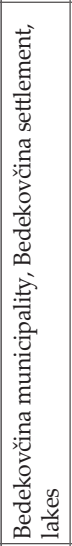 & 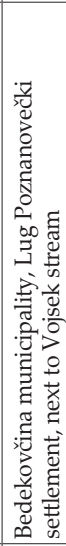 & 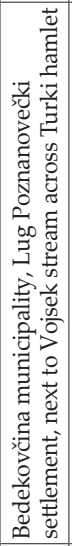 & 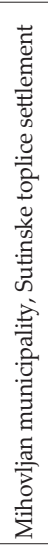 & 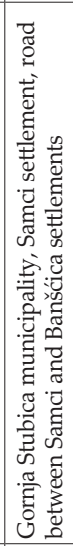 & 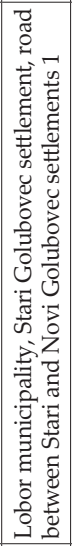 & 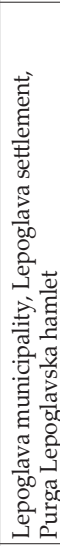 & 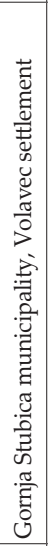 & 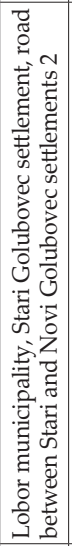 & 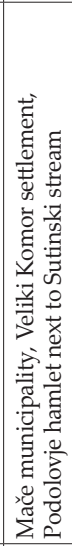 & 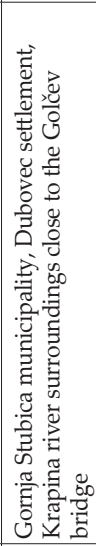 & 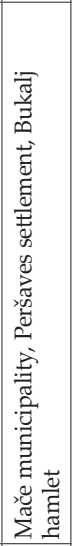 & 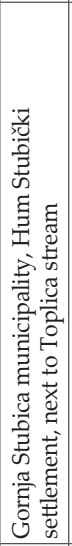 & 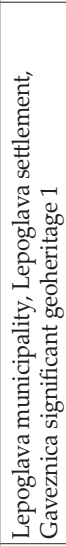 & 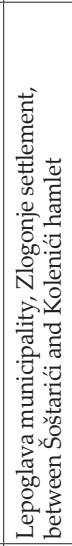 & 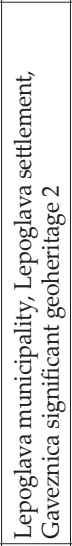 & 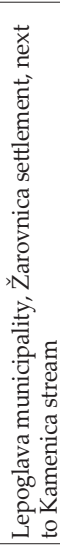 \\
\hline 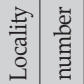 & เి & : & $\Xi$ & త్ర & ? & 형 & $\stackrel{18}{\circ}$ & $\stackrel{\circ}{\circ}$ & $\stackrel{\widehat{\theta}}{\sigma}$ & $\stackrel{\infty}{\circ}$ & $\stackrel{\circ}{\sigma}$ & $\stackrel{9}{9}$ & 드 & 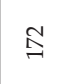 & $\stackrel{\Omega}{\Omega}$ & $\stackrel{\text { In }}{\underline{\Delta}}$ & 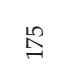 \\
\hline
\end{tabular}




\begin{tabular}{|c|c|c|c|c|c|c|c|c|c|c|c|c|c|}
\hline صّ & 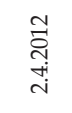 & 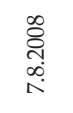 & $\begin{array}{l}\text { त्: } \\
\text { तु. } \\
\text { ठें }\end{array}$ & 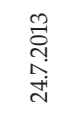 & 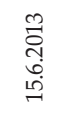 & $\begin{array}{l}\infty \\
\stackrel{\sim}{0} \\
\infty \\
\infty \\
\end{array}$ & $\begin{array}{l}m \\
\stackrel{\sim}{0} \\
\infty \\
\infty \\
\infty\end{array}$ & 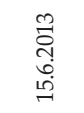 & 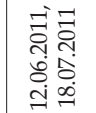 & 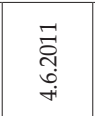 & 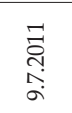 & 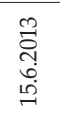 & 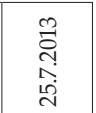 \\
\hline z & 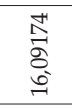 & 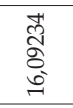 & 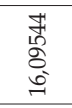 & 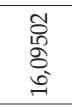 & 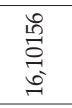 & 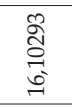 & 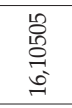 & 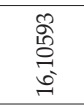 & 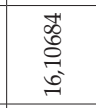 & $\begin{array}{l}\infty \\
0 \\
0 \\
6 \\
6 \\
0\end{array}$ & 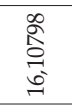 & 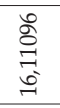 & 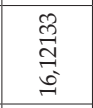 \\
\hline w & 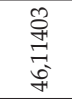 & 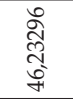 & $\begin{array}{l}0 \\
0 \\
8 \\
8 \\
6 \\
+1\end{array}$ & $\begin{array}{l}\text { ڤ్ర } \\
\text { స్ } \\
\text { రू }\end{array}$ & 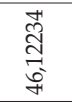 & 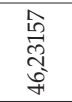 & 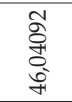 & 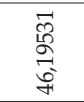 & 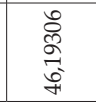 & $\begin{array}{l}\overrightarrow{0} \\
\frac{2}{4} \\
\bar{f}\end{array}$ & 疍 & 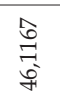 & 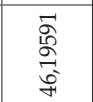 \\
\hline 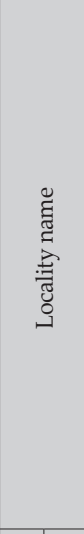 & 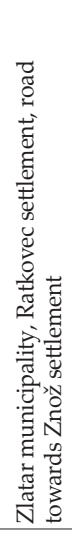 & 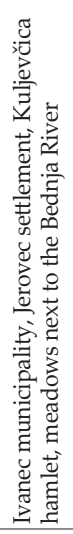 & 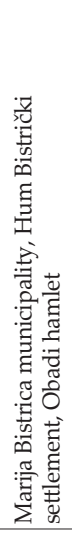 & 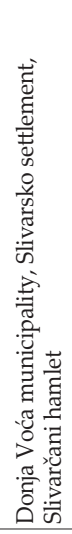 & 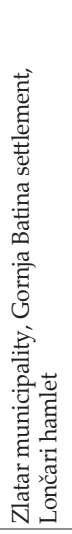 & 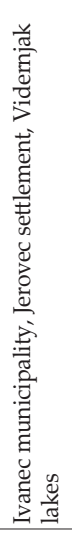 & 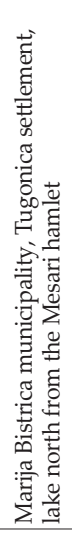 & 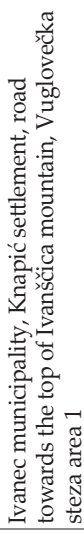 & 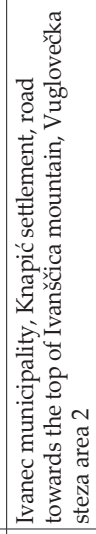 & 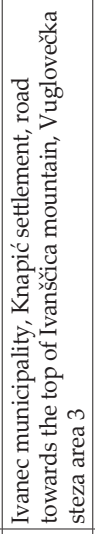 & 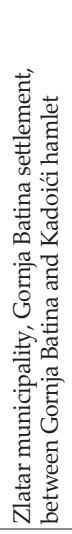 & 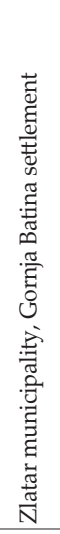 & 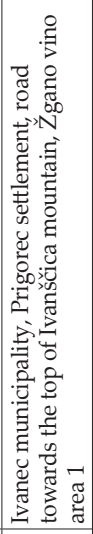 \\
\hline 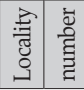 & ๙ి & 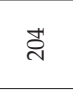 & 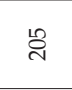 & ఫి & సิ & $\stackrel{\text { ¿े }}{\circ}$ & ટે & $\stackrel{\text { స }}{ }$ & $\bar{\nabla}$ & సี & $\stackrel{m}{\vec{N}}$ & $\vec{d}$ & $\stackrel{\operatorname{Ln}}{\sim}$ \\
\hline
\end{tabular}

\begin{tabular}{|c|c|c|c|c|c|c|c|c|c|c|c|c|c|}
\hline$\frac{\mathscr{\nu}}{\pi}$ & 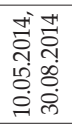 & $\begin{array}{l}m \\
\stackrel{\sim}{\sim} \\
\text { ळ. } \\
\infty\end{array}$ & 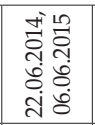 & $\begin{array}{l}\text { İ: } \\
\text { त̦ } \\
\stackrel{\text { in }}{+}\end{array}$ & 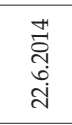 & 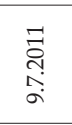 & 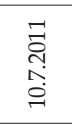 & 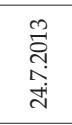 & 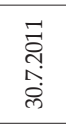 & $\begin{array}{l}\text { ते } \\
\text { సై } \\
\text { तें }\end{array}$ & 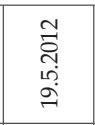 & 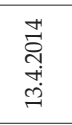 & $\begin{array}{l}\infty \\
\stackrel{\sim}{\Lambda} \\
\infty \\
\stackrel{1}{\wedge}\end{array}$ \\
\hline$z$ & $\begin{array}{l}\vec{\sigma} \\
\text { ô. } \\
\text { ơ }\end{array}$ & 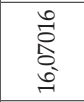 & 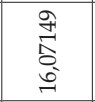 & $\begin{array}{l}\text { 岕 } \\
\text { 今ે } \\
\text { ف. }\end{array}$ & 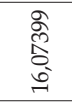 & 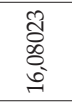 & 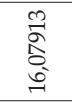 & 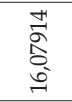 & $\begin{array}{l}\text { ồ } \\
\text { o } \\
\text { s. }\end{array}$ & 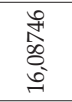 & 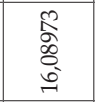 & 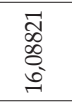 & $\begin{array}{l}\infty \\
\infty \\
\infty \\
0 \\
0 \\
0\end{array}$ \\
\hline س & 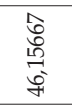 & 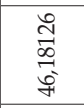 & 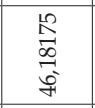 & 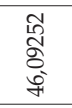 & 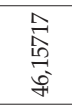 & 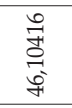 & 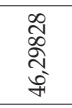 & 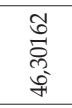 & 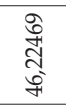 & $\begin{array}{l}\text { בี } \\
\text { E⿱ } \\
\text { \&े }\end{array}$ & 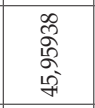 & 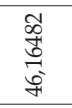 & $\begin{array}{l}\text { Õ } \\
\text { స్ } \\
\text { Lे }\end{array}$ \\
\hline 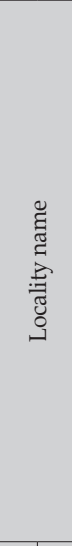 & 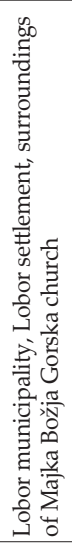 & 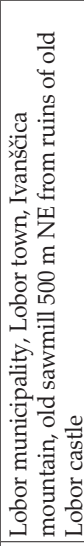 & 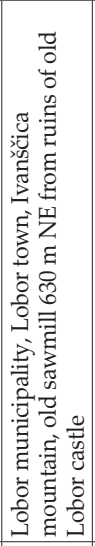 & 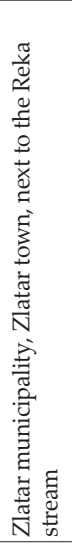 & 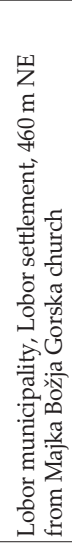 & 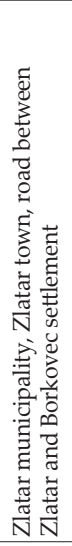 & 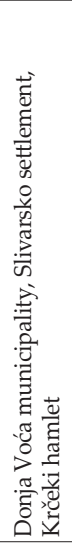 & 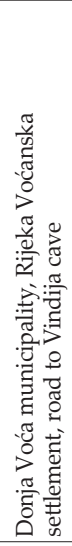 & 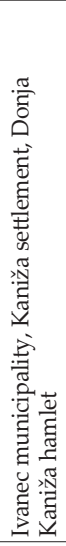 & 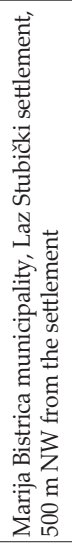 & 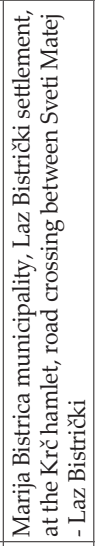 & 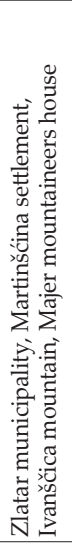 & 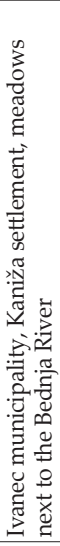 \\
\hline 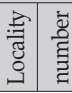 & $\stackrel{8}{9}$ & $\sqrt{2}$ & ऽี & $\stackrel{\Omega}{\Omega}$ & 艺 & $\stackrel{2}{g}$ & $\stackrel{2}{2}$ & 응 & $\stackrel{\infty}{\stackrel{2}{2}}$ & gे & ః्స & $\overline{\text { ปี }}$ & $\bar{\pi}$ \\
\hline
\end{tabular}




\begin{tabular}{|c|c|c|c|c|c|c|c|c|c|c|c|c|c|c|c|c|}
\hline ص̃ & 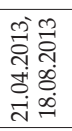 & 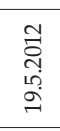 & 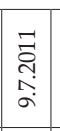 & $\begin{array}{l}\text { ב̃ } \\
\text { जิ } \\
\text { तi }\end{array}$ & $\begin{array}{l}m \\
\stackrel{m}{c} \\
\infty \\
\infty \\
\infty \\
\infty\end{array}$ & 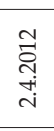 & 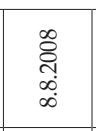 & 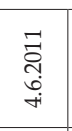 & $\begin{array}{l}\infty \\
\stackrel{0}{0} \\
\infty \\
\infty \\
\infty \\
\infty\end{array}$ & $\begin{array}{l}\infty \\
\stackrel{\sim}{0} \\
\infty \\
\infty \\
\infty\end{array}$ & $\begin{array}{l}\infty \\
\stackrel{\leftrightarrow}{0} \\
\infty \\
\infty \\
\end{array}$ & $\begin{array}{l}\text { ڤ్ర } \\
\text { त़ } \\
\text { ம் }\end{array}$ & 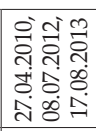 & 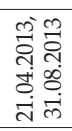 & 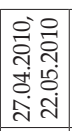 & 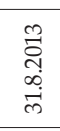 \\
\hline z & 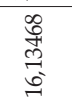 & $\begin{array}{l}\infty \\
\mathbb{6} \\
0 \\
\vec{b}\end{array}$ & 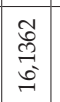 & 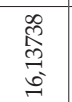 & 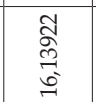 & 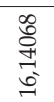 & $\begin{array}{l}\text { 量 } \\
\text { 点 }\end{array}$ & 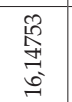 & 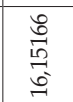 & 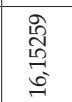 & 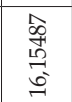 & 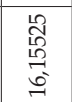 & 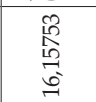 & $\begin{array}{l}\infty \\
8 \\
0 \\
6 \\
0\end{array}$ & 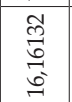 & 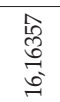 \\
\hline$\omega$ & $\begin{array}{l}\text { ô } \\
\text { Fे } \\
\text { क् }\end{array}$ & $\begin{array}{l}\text { ô } \\
\text { o } \\
\text { bi }\end{array}$ & 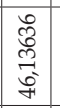 & 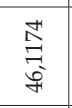 & 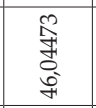 & $\begin{array}{l}\vec{b} \\
0 \\
9 \\
\text { sot }\end{array}$ & $\begin{array}{l}\frac{\infty}{2} \\
\frac{1}{4}\end{array}$ & 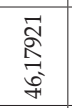 & 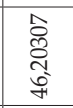 & 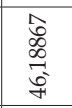 & 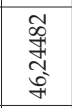 & $\begin{array}{l}\vec{\sigma} \\
\infty \\
\vec{\sigma}+\end{array}$ & $\begin{array}{l}\text { Na } \\
\text { oे } \\
\text { के }\end{array}$ & 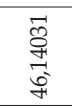 & $\begin{array}{l}10 \\
0 \\
0 \\
0 \\
0 \\
6+1\end{array}$ & 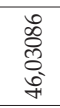 \\
\hline 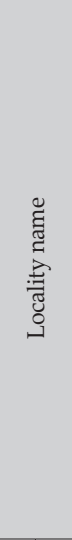 & 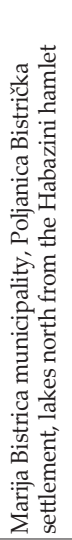 & 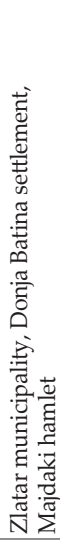 & 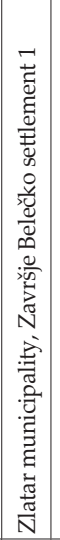 & 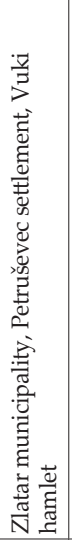 & 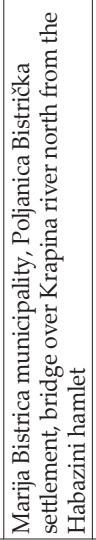 & 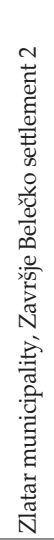 & 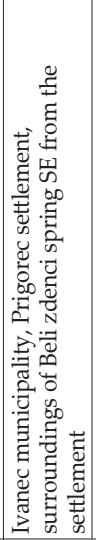 & 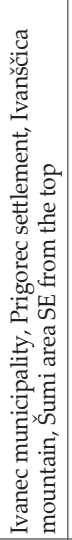 & 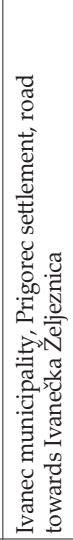 & 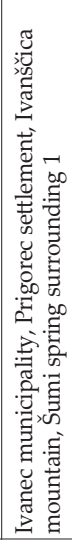 & 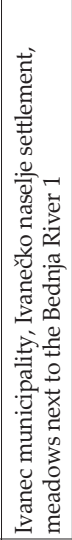 & 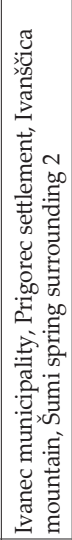 & 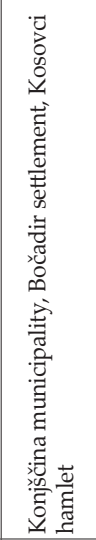 & 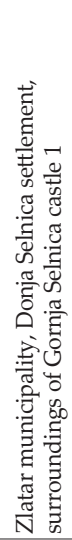 & 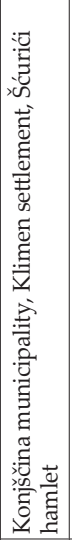 & 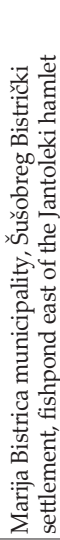 \\
\hline 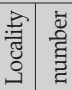 & તે & సి & సે & ల్లి & $\vec{\nabla}$ & $\widetilde{\approx}$ & $\widetilde{\sim}$ & तై & $\stackrel{\text { ㅁ }}{\sim}$ & ஜ్రి & $\widehat{\widehat{N}}$ & $\ddot{\sim}$ & ले & 웟 & ت্ন & \\
\hline
\end{tabular}

\begin{tabular}{|c|c|c|c|c|c|c|c|c|c|c|c|}
\hline ฮँ & 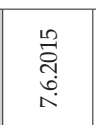 & 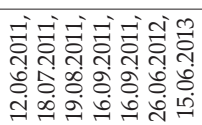 & 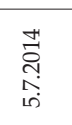 & 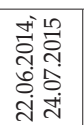 & 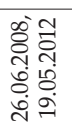 & 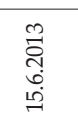 & 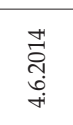 & 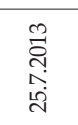 & 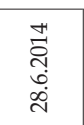 & 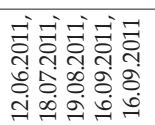 & 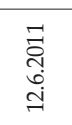 \\
\hline z & 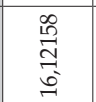 & 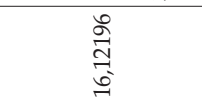 & $\begin{array}{l}\text { ले } \\
\text { స్ }\end{array}$ & 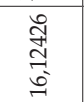 & 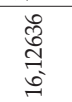 & 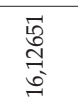 & $\begin{array}{l}\text { సิ } \\
\text { ప) }\end{array}$ & 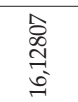 & 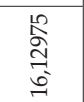 & 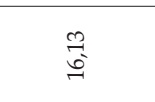 & 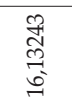 \\
\hline س & 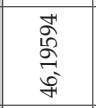 & 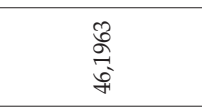 & $\begin{array}{l}\vec{m} \\
\infty \\
0 \\
\vec{f}\end{array}$ & 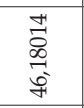 & 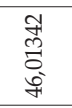 & 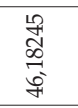 & 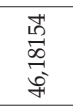 & $\begin{array}{l}\mathbb{H} \\
\text { o } \\
0 \\
\text { tid }\end{array}$ & 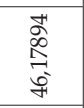 & 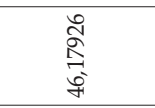 & 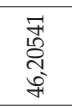 \\
\hline 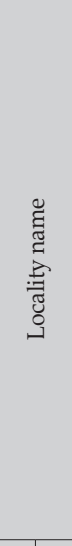 & 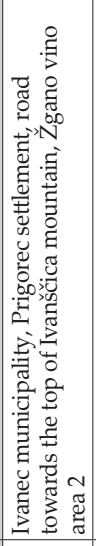 & 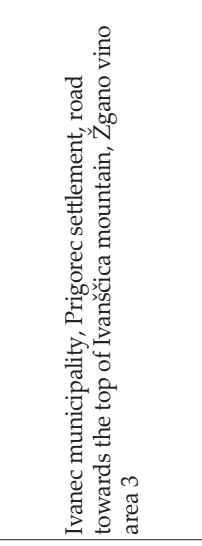 & 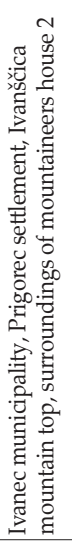 & 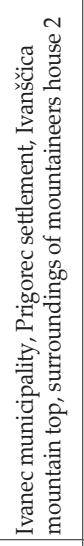 & 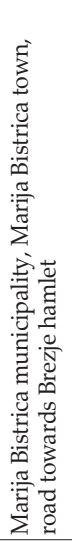 & 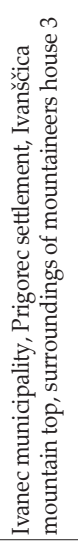 & 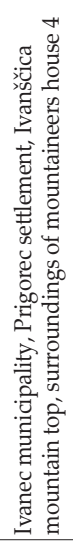 & 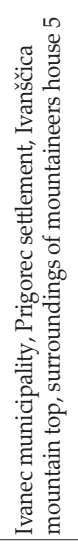 & 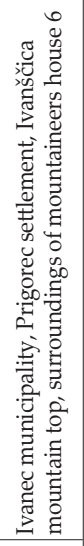 & 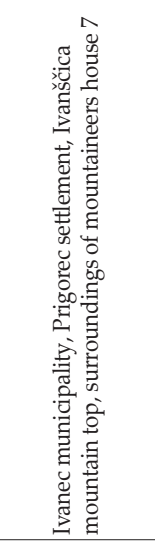 & 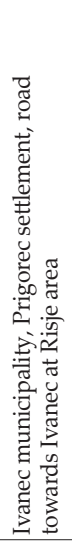 \\
\hline 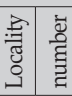 & $\vec{\sim}$ & $\overrightarrow{\vec{\lambda}}$ & $\stackrel{\infty}{\sim}$ & $\vec{\nabla}$ & สิ & $\overrightarrow{\boldsymbol{A}}$ & สี & సి & $\mathbb{ה}$ & $\stackrel{\stackrel{ }{*}}{ }$ & สి \\
\hline
\end{tabular}




\begin{tabular}{|c|c|c|c|c|c|c|c|c|c|c|c|c|c|c|c|c|c|c|}
\hline 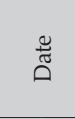 & 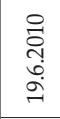 & 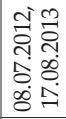 & 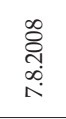 & $\begin{array}{l}\text { ते } \\
\stackrel{+}{+} \\
\vec{i}\end{array}$ & \begin{tabular}{l}
$\infty$ \\
\multirow{్}{0}{} \\
$\infty$ \\
$\infty$ \\
$\infty$
\end{tabular} & 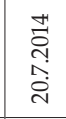 & 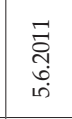 & 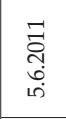 & 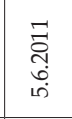 & 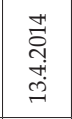 & $\begin{array}{l}m \\
\stackrel{a}{0} \\
\infty \\
\infty \\
\dot{m}\end{array}$ & 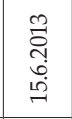 & 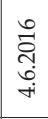 & 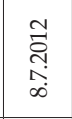 & $\begin{array}{l}\widetilde{N} \\
\stackrel{\sim}{1} \\
\underset{\infty}{\infty}\end{array}$ & 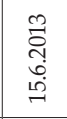 & 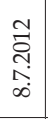 & 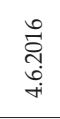 \\
\hline$z$ & 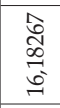 & 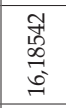 & 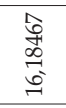 & 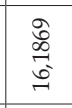 & 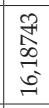 & 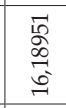 & $\begin{array}{l}\text { oे } \\
\text { aे } \\
\text { bे }\end{array}$ & 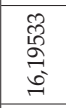 & $\begin{array}{l}\text { के } \\
\stackrel{0}{2} \\
\overrightarrow{6}\end{array}$ & 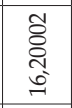 & 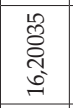 & 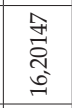 & 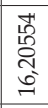 & 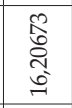 & 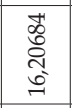 & 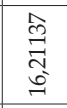 & 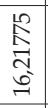 & 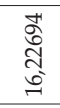 \\
\hline 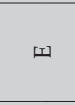 & 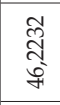 & 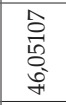 & 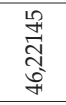 & \begin{tabular}{l}
$\sqrt{n}$ \\
An \\
\multirow{5}{5}{} \\
4
\end{tabular} & 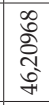 & 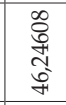 & 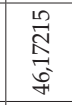 & 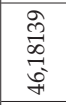 & 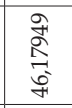 & 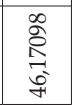 & 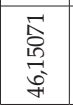 & 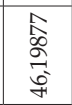 & 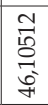 & 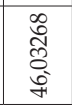 & 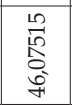 & $\begin{array}{l}\overline{5} \\
\text { \% } \\
\stackrel{5}{5}\end{array}$ & 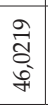 & 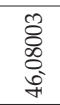 \\
\hline 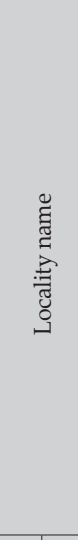 & 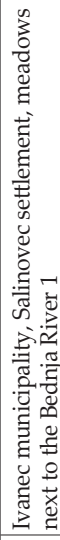 & 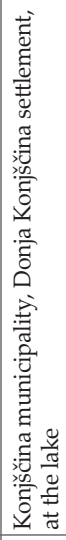 & 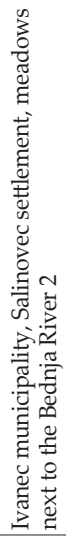 & 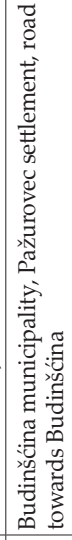 & 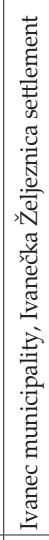 & 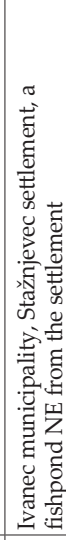 & 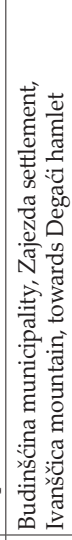 & 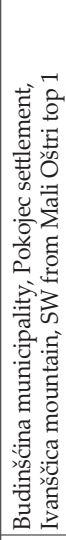 & 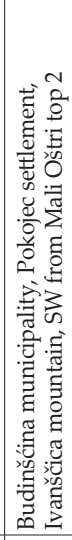 & 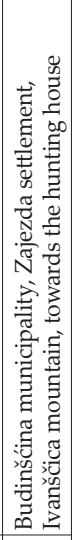 & 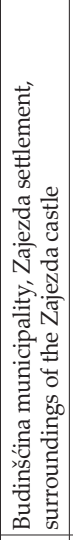 & 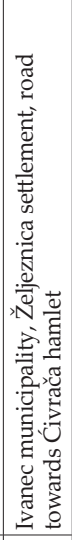 & 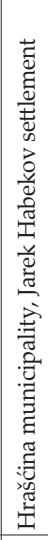 & 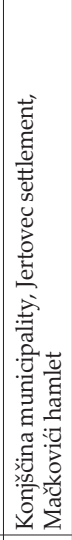 & 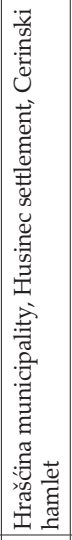 & 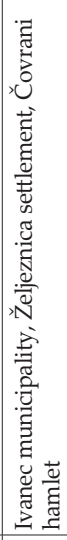 & 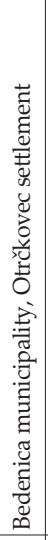 & 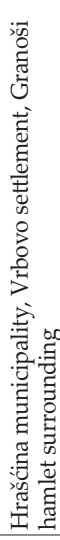 \\
\hline 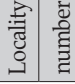 & $\stackrel{\infty}{\sim}$ & ڤે & తి & $\overrightarrow{\mathrm{N}}$ & త్రి & B & 芯 & 岂 & లె & $\widehat{\mathrm{N}}$ & $\stackrel{\infty}{*}$ & సे & ลิ & స & ลิ & సิ & तે & $\stackrel{\text { ก }}{\text { N }}$ \\
\hline
\end{tabular}

\begin{tabular}{|c|c|c|c|c|c|c|c|c|c|c|c|c|c|c|c|}
\hline ڤँّ & 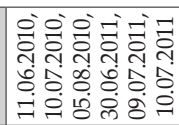 & 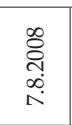 & 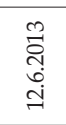 & $\begin{array}{l}\text { ते } \\
\text { तิ } \\
\text { ते }\end{array}$ & 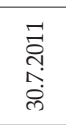 & $\begin{array}{l}m \\
\stackrel{\text { जे }}{1} \\
\infty \\
\dot{m}\end{array}$ & 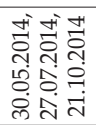 & 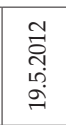 & 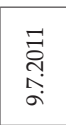 & 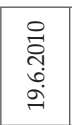 & 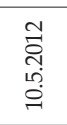 & 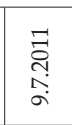 & 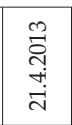 & 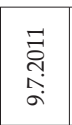 & $\begin{array}{l}\text { בิ } \\
\text { तิ } \\
\text { مุ }\end{array}$ \\
\hline z & $\begin{array}{l}0 \\
0 \\
0 \\
0 \\
0 \\
0\end{array}$ & 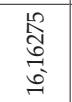 & 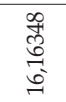 & 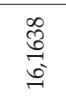 & 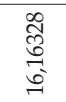 & 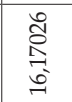 & $\begin{array}{l}\infty \\
8 \\
0 \\
6 \\
0\end{array}$ & $\begin{array}{l}\text { ले } \\
\text { స్ } \\
\text { "' }\end{array}$ & 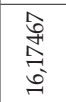 & 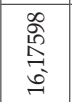 & 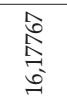 & 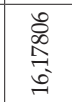 & 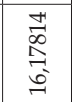 & 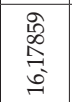 & 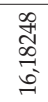 \\
\hline س & 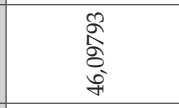 & 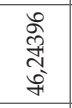 & 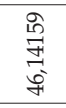 & 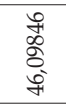 & 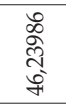 & 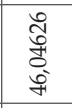 & 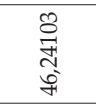 & 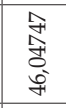 & 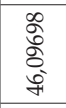 & $\begin{array}{l}\infty \\
\infty \\
\infty \\
\\
\text { సீ }\end{array}$ & $\begin{array}{l}\overrightarrow{1} \\
\infty \\
0 \\
0 \\
0 \\
0\end{array}$ & 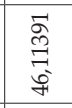 & 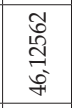 & 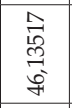 & $\begin{array}{l}\text { 令 } \\
\text { S } \\
\text { ơ }\end{array}$ \\
\hline 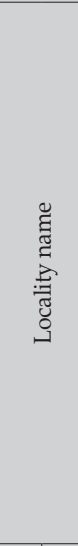 & 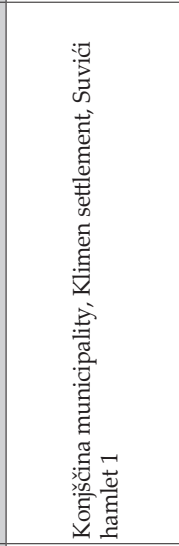 & 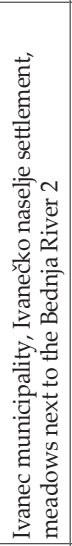 & 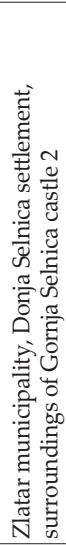 & 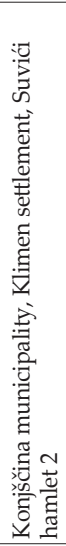 & 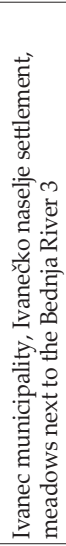 & 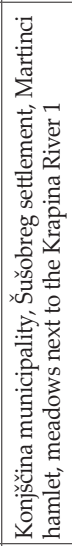 & 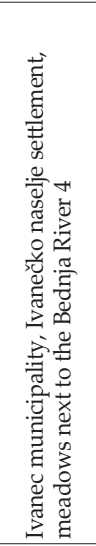 & 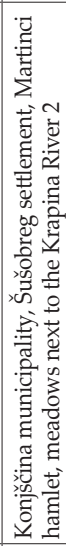 & 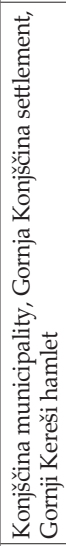 & 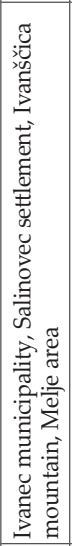 & 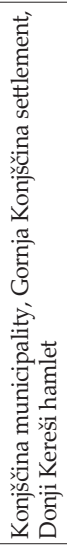 & 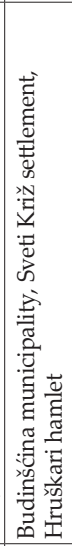 & 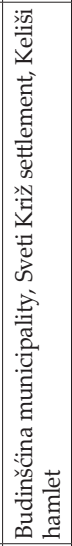 & 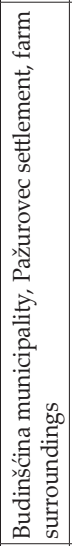 & 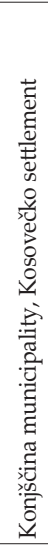 \\
\hline 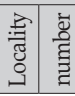 & $\stackrel{\text { I }}{\mathrm{N}}$ & 芯 & 㝵 & $\stackrel{\text { I }}{N}$ & 今 & $\stackrel{\infty}{\mathrm{N}}$ & ఫ্ & ్ㅠ & $\overrightarrow{\mathrm{N}}$ & నิ & בֶ] & 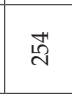 & 吕 & ڤั & 忩 \\
\hline
\end{tabular}




\begin{tabular}{|c|c|c|c|c|c|c|c|c|}
\hline صี & $\begin{array}{l}\stackrel{m}{\vec{i}} \\
\underset{+}{+} \\
\vec{\sim}\end{array}$ & 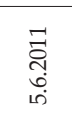 & 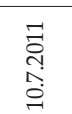 & 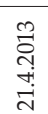 & 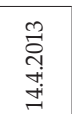 & 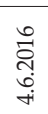 & 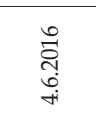 & $\begin{array}{l}\stackrel{m}{2} \\
\stackrel{i}{+} \\
\stackrel{+}{+}\end{array}$ \\
\hline z & 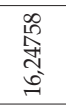 & 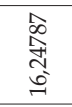 & 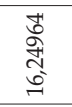 & 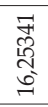 & 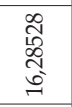 & $\begin{array}{l}\text { o } \\
\text { o. } \\
0 \\
0 \\
0\end{array}$ & 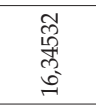 & 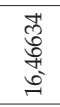 \\
\hline w & 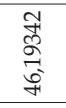 & $\begin{array}{l}\text { ôे } \\
\sigma \\
\frac{2}{5}\end{array}$ & 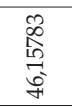 & 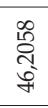 & 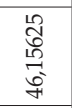 & 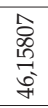 & 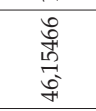 & 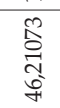 \\
\hline 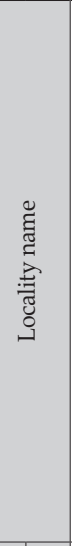 & 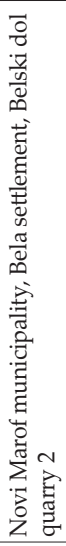 & 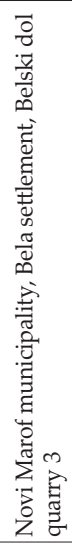 & 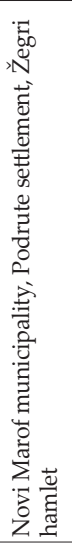 & 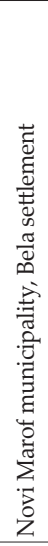 & 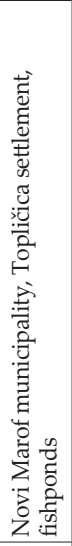 & 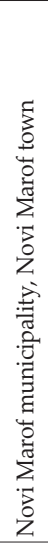 & 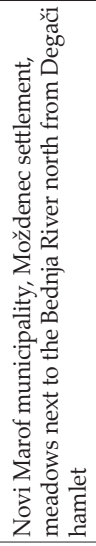 & 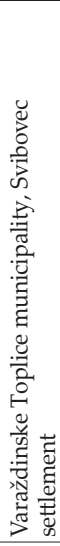 \\
\hline 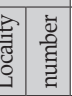 & $\underset{\sim}{\mathbb{N}}$ & $\underset{\sim}{\sim ్}$ & 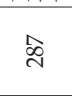 & $\stackrel{\infty}{\infty}$ & ळे & ঃ্ন & $\overline{\text { ন }}$ & \\
\hline
\end{tabular}

\begin{tabular}{|c|c|c|c|c|c|c|c|c|c|}
\hline صّ & 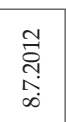 & 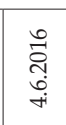 & 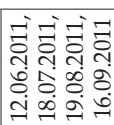 & $\begin{array}{l}\vec{\nabla} \\
\text { त़े } \\
\text { ம் }\end{array}$ & \begin{tabular}{l}
\multirow{2}{*}{} \\
$\stackrel{\sim}{\wedge}$ \\
$\infty$ \\
$\infty$
\end{tabular} & 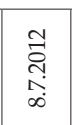 & 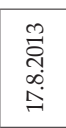 & 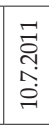 & 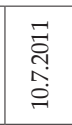 \\
\hline z & $\begin{array}{l}\text { तี } \\
\text { సู } \\
\text { ֻ }\end{array}$ & 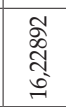 & 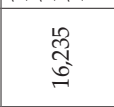 & 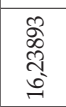 & 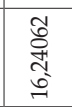 & $\begin{array}{l}\text { Iี } \\
\text { İ: } \\
\text { ปू }\end{array}$ & 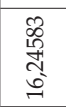 & 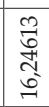 & 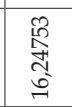 \\
\hline$\omega$ & 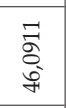 & 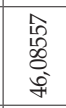 & 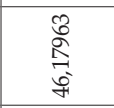 & $\begin{array}{l}\vec{\sigma} \\
\vec{\infty} \\
\vec{f}\end{array}$ & 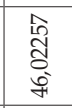 & 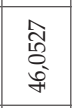 & 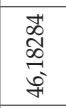 & 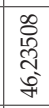 & $\begin{array}{l}\vec{F} \\
\frac{7}{2} \\
\frac{9}{5}\end{array}$ \\
\hline 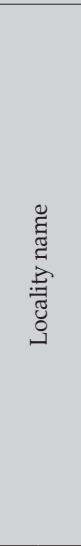 & 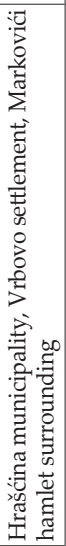 & 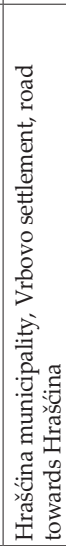 & 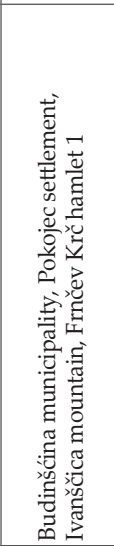 & 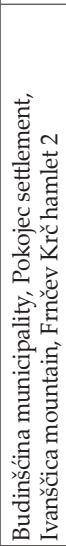 & 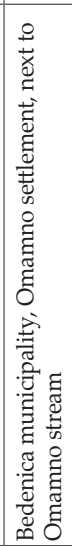 & 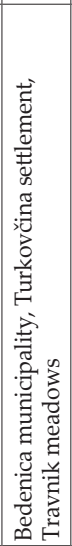 & 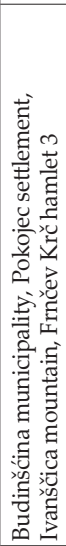 & 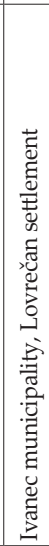 & 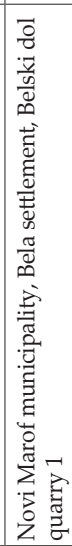 \\
\hline 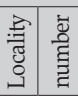 & ฝ̊ & 太ิ & $\stackrel{\infty}{\text { ลे }}$ & ฝે & ఖ్సి & $\overrightarrow{\sim ్ d}$ & స్తి & वి & \\
\hline
\end{tabular}

